\title{
Minimizing Repolarization-Related Proarrhythmic Risk in Drug Development and Clinical Practice
}

\author{
Attila S. Farkas ${ }^{1}$ and Stanley Nattel ${ }^{1,2}$
}

1 Department of Medicine and Research Center, Montreal Heart Institute and University of Montreal, Montreal, Quebec, Canada

2 Department of Pharmacology, McGill University, Montreal, Quebec, Canada

\section{Contents}

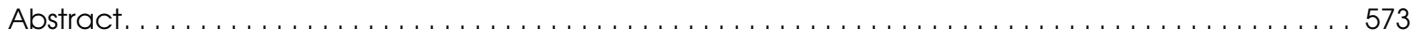

1. Proarrhythmia and Drug Development. . . . . . . . . . . . . . . . . . . . . . . . . 575

1.1 Long QT Syndrome (LQTS) and the Mechanism of Torsades de Pointes (TdP) . . . . . . . . . 576

1.2 Predicting TdP . . . . . . . . . . . . . . . . . . . . . . . . . . . . . . . . 577

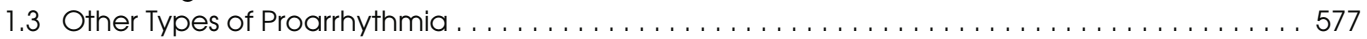

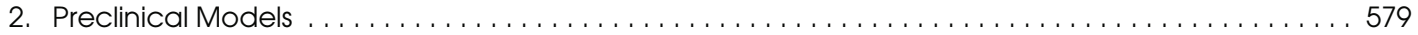

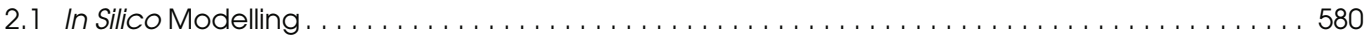

2.2 In Vitro Models. . . . . . . . . . . . . . . . . . . . . . . . . . . . . . . . . . . . . . . . . . 581

2.2. 1 Human Ether-à-Go-Go (hERG) Subunit Assay . . . . . . . . . . . . . . . . . . . . . . . . . 583

2.2.2 Purkinje Fibre and Papillary Muscle Action Potential Duration Assays . . . . . . . . . . . . . . 584

2.2 .3 Arterially Perfused Wedge Preparations . . . . . . . . . . . . . . . . . . . . . . . . . . 585

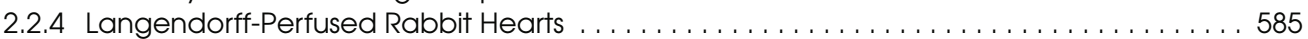

2.3 In Vivo TdP Models . . . . . . . . . . . . . . . . . . . . . . . . . . . . . . . . 586

2.3.1 In Vivo Studies in Normal Animals . . . . . . . . . . . . . . . . . . . . . . . . . . . . . . . . . . 587

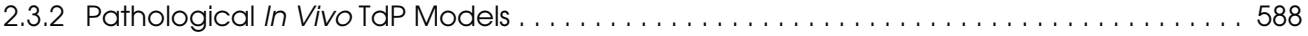

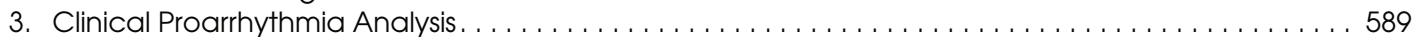

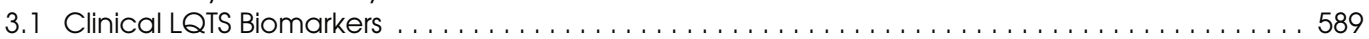

3.2 'Thorough QT Study' . . . . . . . . . . . . . . . . . . . . . . . . . . . . . . . . . . . . . 590

4. Detecting and Preventing Proarrhythmia in Clinical Practice . . . . . . . . . . . . . . . . 591

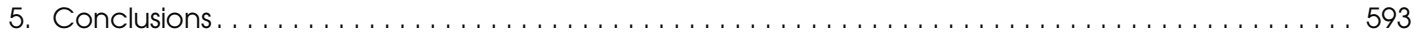

\section{Abstract}

Proarrhythmia, the development of new or worse arrhythmias in response to drug therapy, is a major limitation to the development and use of new drugs. There are different types of drug-induced proarrhythmia, including long-QT syndrome (LQTS), short-QT syndrome and proarrhythmia related to $\mathrm{Na}^{+}$-channel blockade/conduction impairment. By far the most important form of proarrhythmia at present is drug-induced LQTS and its associated characteristic tachyarrhythmia, torsades de pointes (TdP). TdP arises when cellular action potentials (APs) are excessively prolonged, leading to arrhythmogenic afterdepolarizations, especially early afterdepolarizations (EADs), which trigger complex re-entry in a substrate involving increased transmural 
dispersion of repolarization. In vitro screening, increasingly involving highthroughput assays, is used to assess potential candidate molecules and eliminate potentially problematic structures at an early stage of development. The most commonly used screening assays assess drug block of the $\mathrm{K}^{+}$current carried by human ether-à-go-go (hERG) subunits, corresponding to the rapid delayed-rectifier $\mathrm{K}^{+}$channel, the overwhelmingly most common target of TdP-inducing drugs. In addition, the effects of drugs on AP duration or the in vivo equivalent, QT interval, are often assessed in animal models. Methods available for repolarization-related proarrhythmic risk assessment include in vitro (Langendorff-perfused rabbit or guinea pig hearts) and in vivo models (such as $\alpha$-adrenoceptor-stimulated rabbits, rabbits with reduced repolarization reserve due to block of slow delayed-rectifier current, animals with chronic atrioventricular block or animals with cardiac remodelling caused by congestive heart failure). In silico modelling may be helpful for molecular design of non-hERG blocking candidates and for optimization of compound selection (at the molecular and pharmacological profile levels). Finally, clinical evaluation of effects on electrocardiographic intervals (particularly QT) and cardiac rhythm are often needed, both prior to drug approval and after successful introduction on the market (postmarketing surveillance). The successful avoidance of proarrhythmic complications is a shared responsibility of the innovative pharmaceutical industry, regulatory authorities, partners in the clinical drug development phase and practicing physicians. This paper reviews the principal forms of proarrhythmia and the methods that can be used to minimize the risk of proarrhythmia in drug development and clinical practice, with particular emphasis on the most common and problematic form, acquired LQTS.

For every year since 1900, except 1918, cardiovascular diseases accounted for more deaths than any other single cause of death in the US. ${ }^{[1]}$ Nearly 2400 Americans die of cardiovascular disease each day, an average of one death every 37 seconds. ${ }^{[1]}$ Estimates for the US range from $<200000$ to $>450000$ sudden cardiac deaths (SCDs) annually. ${ }^{[2]}$ In most cases the cause of SCD is ventricular tachyarrhythmia, in particular ventricular fibrillation (VF). ${ }^{[2]}$ In the 1970s, pharmaceutical companies developed a great number of antiarrhythmic drugs, hoping to be able to prevent cardiac arrhythmic episodes and associated subsequent deaths. However, the CAST (Cardiac Arrhythmia Suppression Trial) ${ }^{[3]}$ and SWORD (Survival With Oral d-Sotalol) ${ }^{[4]}$ studies provided evidence that Vaughan-Williams Class IC $\mathrm{Na}^{+}$-current $\left(\mathrm{I}_{\mathrm{Na}}\right.$ ) blockers and Class III rapid delayed-rectifier $\mathrm{K}^{+}$-current $\left(\mathrm{I}_{\mathrm{Kr}}\right)$ blockers both induce significant arrhythmia risk- enhancement (albeit via different mechanisms). These observations sensitized the medical community to the risks of 'proarrhythmia', defined as the production of de novo arrhythmias or aggravation of existing arrhythmias. Drug-induced proarrhythmia episodes were first described in patients receiving quinidine. ${ }^{[5,6]}$ Later, proarrhythmia was established to be a problem with a variety of non-cardiac drugs that can cause arrhythmias as an idiosyncratic adverse reaction. ${ }^{[7]}$

A specific ECG pattern, with twisting points and undulating peaks, often associated with proarrhythmia by drugs that cause QT prolongation was recognized by Desertenne, who coined the descriptive French term 'torsades de pointes' (TdP), meaning 'twisting of the points'. ${ }^{[8]}$ TdP has a characteristic pathophysiology (figure 1a, discussed in detail in section 1.1) and can manifest as acutely decreased pump function and haemodynamic instability, leading to syncope (sometimes 
a

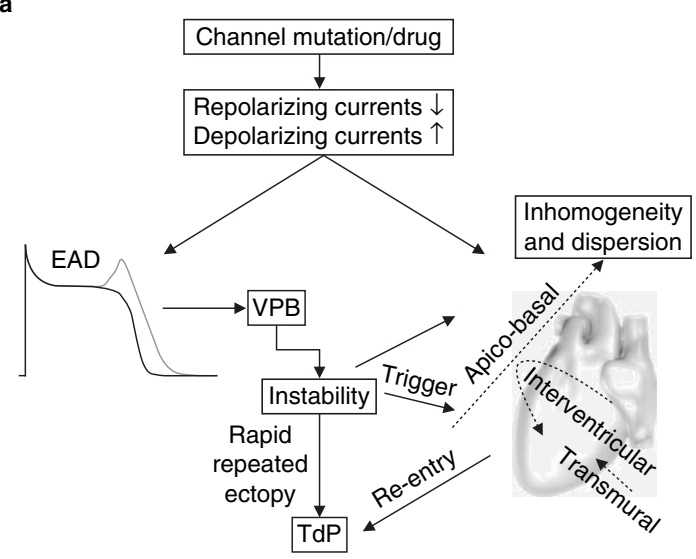

b
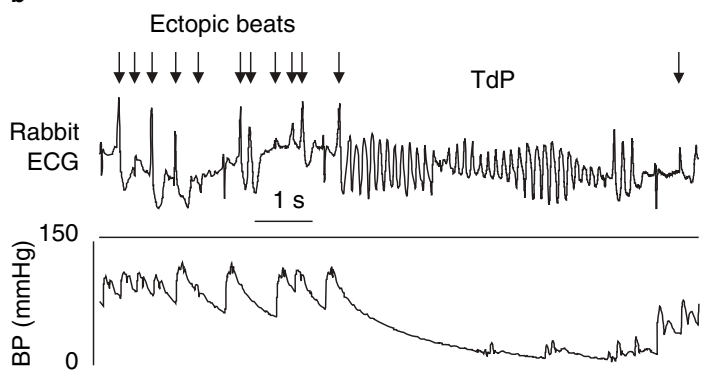

Fig. 1. Mechanisms and ECG appearance of torsades de pointes (TdP). (a) Mechanism of TdP arrhythmia. (b) TdP in an $\alpha_{1}$-adrenoceptor-stimulated anaesthetized rabbit. ECG and arterial blood pressure (BP) before and during arrhythmia. Arrows indicate ectopic beats before TdP. EAD = early afterdepolarization; VPB = ventricular premature beat; $\uparrow$ indicates increase; $\downarrow$ indicates decrease.

with seizure-like activity), or via transformation to VF, causing SCD (figure $1 b$ ).

Although a variety of mechanisms can cause proarrhythmia, the most significant in drug development and clinical practice are those related to abnormal repolarization, which is the focus of this paper. The objectives of this review are to summarize the presently available preclinical and clinical models for assessing proarrhythmic risk, and to provide information about how repolarization-related proarrhythmia can be minimized in clinical practice.

\section{Proarrhythmia and Drug Development}

Because of concern about proarrhythmic risks, new chemical entities are generally screened for biomarkers of proarrhythmia liability early during drug discovery and development. Basic pharmacological and toxicological studies may detect proarrhythmia forms such as ventricular premature beats (VPBs), ventricular salvoes or conduction block. For instance, inward L-type calcium current $\left(\mathrm{I}_{\mathrm{CaL}}\right)$ blockers evoke atrioventricular (AV) block at higher concentrations. ${ }^{[9-11]}$ Catecholamines may induce VPBs and catecholaminergic polymorphic ventricular tachycardia (CPVT). The AV-block dog model is a well developed screen for drug-induced ventricular ectopy associated with TdP. ${ }^{[12]}$ Dose-related proarrhythmia is much easier to detect than proarrhythmia that is only manifest in patients with idiosyncratic predisposition. Many drugs associated with drug-induced $\mathrm{TdP}$ produce proarrhythmia as a rare manifestation, with an incidence $<1$ case in 2000. ${ }^{[13,14]}$ Conventional preclinical and clinical screening methods are not powered to detect these relatively rare events. ${ }^{[15]}$

Electrocardiographic QT-interval prolongation (considered to be a TdP risk biomarker) and TdP have been the single most common cause of withdrawal of marketed drugs in the past decade. ${ }^{[16]}$ Therefore, TdP liability testing has become a key element of contemporary new drug development, since many drugs (including cardiovascular drugs, antibacterials, antifungals, antimalaria drugs, antihistamines, psychotropic agents, gastrointestinal prokinetics and nonadjuvant anticancer agents ${ }^{[17]}$ ) and in some cases even their metabolites may provoke TdP. An up-to-date list can be found at www.torsades.org. Thus, the proarrhythmic liability of any drug under development must be assessed to minimize as much as possible the potential risk that these druginduced life-threatening arrhythmias will occur during pharmacotherapy. ${ }^{[18]}$ Safety pharmacology testing of new drugs is a great financial and practical burden for the pharmaceutical industry; however, it is crucial in preventing the much greater cost of developing an agent that will risk human health and eventually have to be withdrawn for safety reasons. The International Conference on Harmonization (ICH) adopted a preclinical (ICH S7B) and clinical (ICH E14) guidance in 2005, with recommendations for 
testing of new drugs for proarrhythmic, torsadogenic effect. ${ }^{[19,20]}$ Shortly afterwards, the US FDA, European Union and Health Canada adopted these guidelines.

\subsection{Long QT Syndrome (LQTS) and the Mechanism of Torsades de Pointes (TdP)}

At about the time when quinidine-induced TdP proarrhythmia was first described, it was recognized that $\mathrm{TdP}$ can also be caused by inherited arrhythmia syndromes, ${ }^{[21-23]}$ subsequently shown to be most commonly caused by genetic channelopathies. It was also recognized that $\mathrm{TdP}$ is associated with QT prolongation in 'long QT syndromes' (LQTSs), congenital or acquired. A variety of mutations/genetic syndromes (designated 'LQT1-12') and drugs cause abnormal function of ion channels, leading to decreased repolarizing currents (principally the rapid $\left[\mathrm{I}_{\mathrm{Kr}}\right]$ or the slow $\left[\mathrm{I}_{\mathrm{Ks}}\right]$ component of the delayed rectifier potassium current) or to increased depolarizing currents (particularly the late sodium inward current $\left[\mathrm{I}_{\mathrm{Na}}\right]$ and L-type calcium current $\left[\mathrm{I}_{\mathrm{CaL}}\right]$ ) during the action potential (AP) plateau. ${ }^{[2]}$ The vast majority of drugs associated with TdP selectively reduce $\mathrm{I}_{\mathrm{Kr}}$ because of the unique molecular structure of the underlying channel (human ether-à-go-go [hERG] channel), which has a long external vestibule that promotes drug trapping. ${ }^{[13,24]}$

The clinical recognition of $\mathrm{TdP}$ is sometimes difficult because the distinction between various ventricular tachyarrhythmias can be arbitrary, and drug-induced TdP, polymorphic ventricular tachycardia (VT) and VF may represent discrete entities within a spectrum of drug-induced proarrhythmia. ${ }^{[25]}$

A number of hypotheses have been proposed to explain the generation of TdP, but the exact underlying mechanisms remain incompletely understood. It is generally accepted that early afterdepolarizations (EADs) are involved, ${ }^{[26]}$ but whether they only provide triggers for a polymorphic re-entrant tachyarrhythmia or whether they maintain TdP by acting as drivers with variable conduction patterns is uncertain. Figure 1a illustrates the mechanism by which TdP arises.
In the most widely accepted theory, $\mathrm{TdP}$ requires both initiating and maintaining mechanisms. The initiating mechanism is most typically provided by EADs. Any reduction in net repolarizing currents predisposes to EADs, which can lead to ventricular extrasystoles that trigger re-entrant tachyarrhythmias (initiating mechanism). ${ }^{[27]}$ EADs are generated in phase 2 or 3 of a prolonged AP by depolarizing currents that can be carried by $\mathrm{I}_{\mathrm{CaL}}$ and $\mathrm{I}_{\mathrm{Na}}$, but also inward $\mathrm{Na}^{+} / \mathrm{Ca}^{2+}$ exchanger (NCX) current. ${ }^{[28]}$ Ectopic beats also precede EADs in canine TdP models. ${ }^{[29]}$ There is evidence that focal activity generated in Purkinje tissue is the primary trigger for $\mathrm{TdP}$ initiation. ${ }^{[30,31]}$ A growing body of data also suggest that $\mathrm{Ca}^{2+}$-handling abnormalities play an important role in torsadogenesis. ${ }^{[12,28,32-38]}$

The TdP-maintaining mechanism includes the ' 4 dimensions' of dispersion of cardiac repolarization in space and time: (i) transmural dispersion of repolarization (TDR); ${ }^{[39,40]}$ (ii) apico-basal dispersion; ${ }^{[36,41]}$ (iii) interventricular dispersion; ${ }^{[29,42-44]}$ and (iv) temporal dispersion. ${ }^{[45,46]}$ Temporal dispersion includes instability that can be a consequence of the above-mentioned initiating mechanisms. ${ }^{[47]}$ Dispersion leads to increased heterogeneity of refractoriness, which sets the stage for re-entrant arrhythmia generation and maintenance. ${ }^{[27]}$ In a recent study mimicking LQT7 (gain-of-function $\mathrm{I}_{\mathrm{CaL}}$ abnormality) in canine isolated ventricular wedge preparations, ventricular trans-septal dispersion predisposed to $\mathrm{TdP} .{ }^{[48]} \mathrm{TdP}$ is frequently preceded by a short-long-short cycle-length sequence in both congenital and acquired LQTS, with the second (ectopic) beat causing a postextrasystolic pause. ${ }^{[44,49,50]}$ The long cycle (postextrasystolic pause) favours the development of an EAD-induced extrasystole of subendocardial focal origin by increasing TDR, and promotes subsequent re-entry. ${ }^{[51,52]}$ The first ectopic complex and the TdP-inducing ectopic beat are often multifocal but can also be unifocal. ${ }^{[53]}$ The characteristic twisting morphology is attributed to the transient bifurcation of a predominantly single rotating scroll into two simultaneous scroll waves involving the right and left ventricles separately. ${ }^{[54]}$ Atrial tachyarrhythmias, 'atrial torsades de pointes', may also develop in LQTS. ${ }^{[55-58]}$ 


\subsection{Predicting TdP}

It has been estimated that $2-3 \%$ of all drug prescriptions include medications with the potential to induce LQTS. ${ }^{[59]}$ Since most clinical trials are underpowered to detect adverse effects as rare as $\mathrm{TdP}$, reliable surrogate parameters (biomarkers) are needed to predict the proarrhythmic liability of drugs. Because of the limitations of the corrected QT interval (QTc) as a biomarker (see section 3), there is great interest in developing biomarkers with greater predictive value for drug-induced arrhythmias based on clinically relevant and predictable in vitro and in vivo proarrhythmia models. ${ }^{[15,18,36,60-63]}$ The variables that have been suggested to be of potential value in predicting proarrhythmic liability are summarized in table I.

\subsection{Other Types of Proarrhythmia}

Table II summarizes the main characteristics of congenital and corresponding drug-induced forms of proarrhythmia. Theoretically, drugs could cause proarrhythmia by mimicking effects of any of the channelopathies that cause congenital arrhythmia syndromes. Although druginduced proarrhythmia has been produced in experimental models of virtually all congenital forms listed in table II, clinical counterparts have only been described for some.

Quinidine can produce proarrhythmic episodes with properties different from TdP, with wide QRS and monomorphic VT. ${ }^{[16]}$ Similarly, other $\mathrm{Na}^{+}$-channel inhibitors such as Class IC antiarrhythmics (flecainide, encainide, moricizine, propafenone) can lead to VT, as well as to atrial fibrillation conversion to a slower atrial tachyarrhythmia with 1:1 ventricular conduction. ${ }^{[125]}$ The CAST study showed that Class IC antiarrhythmics increase mortality, largely because of proarrhythmic liability, in patients with prior myocardial infarction. ${ }^{[3]}$ Loss-of-function mutations of $\mathrm{I}_{\mathrm{Na}}$ produce $\mathrm{VT} / \mathrm{VF}$ predisposition in the Brugada syndrome. A single mutation in the $\mathrm{I}_{\mathrm{Na}}$ gene (SCN5A) shows a unique overlap of LQT3, Brugada syndrome and progressive conduction defects. ${ }^{[126-128]}$ Brugada syndrome mani- festations can be precipitated by drug exposure in predisposed patients, most typically because of $\mathrm{Na}^{+}$-channel blockade. ${ }^{[116]}$ Although, because of space limitations, this article focuses on proarrhythmia related to abnormal repolarization, the potential importance of other forms of proarrhythmia such as those caused by $\mathrm{I}_{\mathrm{Na}}$-blockers needs recognition.

A complementary condition to LQTS was suggested by the observation that SCD risk is doubled in patients with QT intervals shorter than 400 ms. ${ }^{[129]}$ Gussak et al. ${ }^{[130]}$ first reported a case of hereditary short QT interval with syncope, atrial fibrillation and sudden death. Later, short QT syndrome (SQTS) was characterized as a new clinical entity that can be caused by a variety of mutations (corresponding to specific syndromes designated 'SQT1-5'), all of which lead to enhanced repolarization (either by increasing repolarizing $\mathrm{K}^{+}$-currents or decreasing depolarizing $\mathrm{Ca}^{2+}$-currents), resulting in shorter AP duration (APD) and QT interval. ${ }^{[131-133]}$ Reduced APD decreases refractory period and promotes re-entry. There is also a corresponding drug-induced proarrhythmia syndrome ${ }^{[134]}$ which is much rarer than drug-induced LQTS. APD/ QT-shortening drugs such as hERG activators (RPR260243, PD-118057, mallotoxin, NS1643) and ATP-sensitive potassium channel activators (levcromakalim, nicorandil) can reverse the AP-prolonging effects of dofetilide, ${ }^{[135,136]}$ but also cause significant QT and JT shortening, increased $\mathrm{T}_{\text {peak }}-\mathrm{T}_{\text {end }}$ (see section 2.2.3) and produce profibrillatory effects in isolated hearts. A recently marketed antiepileptic drug, rufinamide, significantly shortened the QT interval during preclinical studies and was labelled with a contraindication in patients with familial SQTS and caution in patients receiving other QT-shortening drugs. ${ }^{[134]}$

Preclinical profiling should be extended to predict these forms of proarrhythmic liability if a signal of $\mathrm{Na}^{+}$-channel blocking or APD/QT shortening risk is obtained. Because of the much lower importance at present of proarrhythmia syndromes other than acquired LQTS, we focus primarily on the detection and prevention of acquired LQTS risk in the rest of this paper. 
Table I. Potential electrophysiological and haemodynamic proarrhythmia parameters for acquired LQTS liability

\begin{tabular}{|c|c|c|c|c|}
\hline \multirow[t]{2}{*}{ Parameter } & \multirow[t]{2}{*}{ Description } & \multirow[t]{2}{*}{ Detection mode and comments } & \multicolumn{2}{|l|}{ References } \\
\hline & & & preclinical & clinical \\
\hline \multicolumn{5}{|c|}{ Incidence of preceding ectopic beats } \\
\hline Ectopic beats & Ventricular premature beats & ECG, MAPD & 44 & 64 \\
\hline $\mathrm{R}$ on $\mathrm{T}$ wave & Ectopic beat falls within the T wave & ECG & 65,66 & 64 \\
\hline \multicolumn{5}{|c|}{ Repolarization morphology } \\
\hline TWA and $\mu \mathrm{V}$-TWA & $\begin{array}{l}\text { Beat-to-beat alternation of the morphology, } \\
\text { amplitude and/or polarity of T wave }\end{array}$ & ECG & & $67-71$ \\
\hline $\mathrm{T}_{\text {peak }} \mathrm{T}_{\text {end }}$ & $\begin{array}{l}\text { Interval between the peak and the end of the } \\
\text { ECG T wave, provides an alternate ECG index } \\
\text { of TDR }\end{array}$ & Precordial ECG leads & $39,72-74$ & $75-77$ \\
\hline Triangulation & Prolongation of $\mathrm{APD}_{30}$ to $\mathrm{APD}_{90}$ & APD & 45 & \\
\hline \multicolumn{5}{|c|}{ Beat-to-beat variability } \\
\hline TWLI & $\begin{array}{l}\text { Root-mean-square of the differences between } \\
\text { corresponding signal values of subsequent } \\
\text { beats }\end{array}$ & At least $100 \mathrm{~T}$ waves & & 78 \\
\hline Instability & $\begin{array}{l}\text { Difference between the upper quartile (the } \\
\text { upper boundary of the lowest } 75 \% \text { of the interval } \\
\text { values) and the lower quartile (the upper } \\
\text { boundary of the lowest } 25 \% \text { of the interval } \\
\text { values) }\end{array}$ & APD, ECG & 35,45 & \\
\hline STV & $\begin{array}{l}\text { Poincaré plot, the width of the plot, orthogonal to } \\
\text { the line-of-identity }\end{array}$ & $\begin{array}{l}\text { MAPD, ECG (at least } 30 \\
\text { consecutive beats) }\end{array}$ & $46,79,80$ & 81,82 \\
\hline LTV & $\begin{array}{l}\text { Poincaré plot, the length of the plot, parallel to } \\
\text { the line-of-identity }\end{array}$ & $\begin{array}{l}\text { MAPD, ECG (at least } 30 \\
\text { consecutive beats) }\end{array}$ & 46 & \\
\hline TI & $\begin{array}{l}\text { Poincaré plot, the median of the distances from } \\
\text { centre gravity }\end{array}$ & $\begin{array}{l}\text { ECG (at least } 30 \text { consecutive } \\
\text { beats) }\end{array}$ & 83 & \\
\hline STI & Poincaré plot, the width of the plot & $\begin{array}{l}\text { ECG (at least } 30 \text { consecutive } \\
\text { beats) }\end{array}$ & 83 & \\
\hline LTI & $\begin{array}{l}\text { Poincare plot, the length of the plot, the distance } \\
\text { to the } x \text { coordinate }\end{array}$ & $\begin{array}{l}\text { ECG (at least } 30 \text { consecutive } \\
\text { beats) }\end{array}$ & 83 & \\
\hline RMS & $\begin{array}{l}\text { Root mean square for a sequence of } \\
\text { consecutive ECG intervals }\end{array}$ & ECG & 35 & \\
\hline RMSSD & $\begin{array}{l}\text { Root mean square of successive differences of } \\
\text { consecutive ECG intervals }\end{array}$ & ECG & 84 & 85 \\
\hline SDSD & $\begin{array}{l}\text { Standard deviation of successive differences of } \\
\text { consecutive ECG intervals }\end{array}$ & ECG & 84 & 85 \\
\hline $\begin{array}{l}\text { pNN50-RR } \\
\text { pNN8-QT }\end{array}$ & $\begin{array}{l}\text { Percentage of successive RR/QT intervals that } \\
\text { differ by }>50 \mathrm{~ms} \text { (human) or }>8 \mathrm{~ms} \text { (rabbit) }\end{array}$ & $\begin{array}{l}\text { ECG, RR interval (human) } \\
\text { ECG, QT interval (rabbit) }\end{array}$ & 86 & 87 \\
\hline \multicolumn{5}{|c|}{ Heart rate-dependent repolarization parameters } \\
\hline QTc & Heart rate corrected QT interval & ECG & 35,86 & 88 \\
\hline QTVI & $\begin{array}{l}\text { Log ratio between the QT interval and heart rate } \\
\text { variabilities, each normalized by the squared } \\
\text { mean of the respective time series }\end{array}$ & $\begin{array}{l}\text { At least } 256 \text { sec ECG segment in } \\
\text { sinus rhythm }\end{array}$ & & 89,90 \\
\hline QTRR hysteresis & $\begin{array}{l}\text { Time scale of the adaptation of QT interval to } \\
\text { heart rate changes }\end{array}$ & $\begin{array}{l}\text { Reflects reverse-use dependence } \\
\text { ECG, sinus rhythm }\end{array}$ & 91,92 & 93 \\
\hline \multicolumn{5}{|c|}{ Autonomic nervous system } \\
\hline BRS & $\begin{array}{l}\text { Heart rate response to blood pressure changes, } \\
\text { indicator of parasympathetic nervous system } \\
\text { function }\end{array}$ & $\begin{array}{l}\text { ECG RR intervals, systolic arterial } \\
\text { blood pressure }\end{array}$ & $86,94,95$ & 96,97 \\
\hline
\end{tabular}


Table I. Contd

\begin{tabular}{|c|c|c|c|c|}
\hline \multirow[t]{2}{*}{ Parameter } & \multirow[t]{2}{*}{ Description } & \multirow[t]{2}{*}{ Detection mode and comments } & \multicolumn{2}{|l|}{ References } \\
\hline & & & preclinical & clinical \\
\hline$\overline{\mathrm{HRT}}$ & $\begin{array}{l}\text { Index of autonomic function defined by the } \\
\text { relationship between initial acceleration and } \\
\text { subsequent deceleration of sinus rhythm } \\
\text { following a ventricular ectopic beat }\end{array}$ & $\begin{array}{l}\text { ECG, parasympathetic } \\
\text { (non-invasive), only in case } \\
\text { of extrasystoles }\end{array}$ & & $98-100$ \\
\hline HRV & Index of temporal heart rate variation & ECG & 101 & $102-104$ \\
\hline SP SAP & $\begin{array}{l}\text { Frequency content analysis of temporal systolic } \\
\text { blood pressure trends, indicator of autonomic } \\
\text { tone }\end{array}$ & $\begin{array}{l}\text { ECG RR intervals, systolic arterial } \\
\text { blood pressure }\end{array}$ & 86 & \\
\hline \multicolumn{5}{|c|}{ Complex parameter } \\
\hline TRlaD & $\begin{array}{l}\text { Triangulation, reverse-use dependence, } \\
\text { instability and dispersion }\end{array}$ & MAPD & 25,45 & \\
\hline \multicolumn{5}{|c|}{ 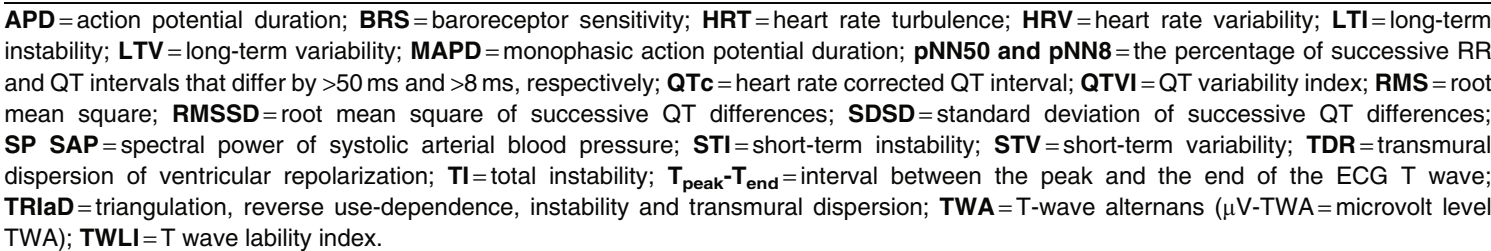 } \\
\hline
\end{tabular}

\section{Preclinical Models}

A working set of recommendations was developed in the early 2000s, known as ICH S7B. The goals of the document were to create a set of standards for the identification of the concentration-related potential of drugs and their metabolites to delay ventricular repolarization. ICH S7B recommends at least a test of direct inhibition of $\mathrm{I}_{\mathrm{Kr}}$ (e.g. hERG assay) and the application of an in vivo model to assess ECG actions and proarrhythmia. If the test substance belongs to a chemical/pharmacological class with members known to prolong QTc in humans, a test for QT prolongation in humans should be performed. The preclinical studies should provide an overall estimate of QT-prolonging risk in humans before the first administration to humans. ${ }^{[19]}$ Finally, an integrated risk assessment should be performed, including the evaluation of preclinical pharmacodynamic and pharmacokinetic data, along with postmarketing surveillance and followup studies relating to clinical QT prolongation.

It has become evident that no single model is sufficient to detect TdP liability completely, and even an integrated combination of approaches cannot successfully estimate the proarrhythmic liability of all drugs. It has therefore been strongly suggested to construct the development programme for each compound on a case by case' basis. ${ }^{[137]}$

Because proarrhythmia liability assays aim for clinical predictive value, the test model must be relevant to human physiology, i.e. species with radically different ionic-current repolarization systems from man (e.g. rat, mouse) should be avoided. The ICH S7B guidelines suggest performing at least two preclinical models before clinical administration.

Clinical TdP is relatively rare, but the incidence of proarrhythmia and sensitivity for proarrhythmic risk detection can be increased in preclinical assays by incorporating risk contributors that promote TdP. For example, slow heart rates and reduced serum $\left[\mathrm{K}^{+}\right]$enhance $\mathrm{TdP}$ likelihood, since lower cardiac frequencies exaggerate APD prolongation due to $\mathrm{hERG}$ blockers (reverse use-dependence) and increase susceptibility to EADs, while decreased $\left[\mathrm{K}^{+}\right]$reduces $\mathrm{I}_{\mathrm{Kr}}$ and background inward-rectifier $\left(\mathrm{I}_{\mathrm{K} 1}\right)$ conductance and enhances sensitivity to hERG blockers. ${ }^{[16]}$ Table III summarizes risk contributors that are incorporated in preclinical assays to enhance their sensitivity. 
Table II. Characteristics of channelopathies with corresponding drug-induced proarrhythmia

\begin{tabular}{|c|c|c|c|c|c|c|c|c|}
\hline Current & Syndrome & Gene & Protein & Mutation function & Drug induced & APD & Arrhythmia & References \\
\hline$\overline{I_{K s} \downarrow}$ & LQT1 & KCNQ1 & KvLQT1 & Loss & $\begin{array}{l}\text { HMR1556 } \\
\text { Chromanol } \\
\text { 293B }\end{array}$ & Lengthened & $\mathrm{TdP}$ & $29,105-107$ \\
\hline $\mathrm{I}_{\mathrm{Ks}} \uparrow$ & SQT2 & $K C N Q 1$ & KvLQT1 & Gain & R-L3 & Shortened & $\mathrm{AF}, \mathrm{VT}, \mathrm{VF}$ & 108,109 \\
\hline$I_{\mathrm{Kr}} \downarrow$ & LQT2 & KCNH2 & hERG & Loss & $\begin{array}{l}\text { Dofetilide } \\
\text { E-4031 }\end{array}$ & Lengthened & $\mathrm{TdP}$ & $110-112$ \\
\hline $\mathrm{I}_{\mathrm{Kr}} \uparrow$ & SQT1 & KCNH2 & $\mathrm{hERG}$ & Gain & $\begin{array}{l}\text { Mallotoxin } \\
\text { NS1643 } \\
\text { PD-118057 } \\
\text { RPR260243 } \\
\text { NS3623 }\end{array}$ & Shortened & $A F, V T, V F$ & $113-115$ \\
\hline$I_{\mathrm{Na}} \downarrow$ & Brugada & SCN5A & Nav1.5 & Loss & $\begin{array}{l}\text { Flecainide } \\
\text { Ajmaline }\end{array}$ & $\begin{array}{l}\text { No effect or } \\
\text { shortened }\end{array}$ & $A F, V T, V F$ & $116-118$ \\
\hline $\mathrm{I}_{\mathrm{Na}} \uparrow$ & LQT3 & SCN5A & Nav1.5 & Gain & $\begin{array}{l}\text { ATX II } \\
\text { Veratridine }\end{array}$ & Lengthened & $\mathrm{TdP}$ & $40,119,120$ \\
\hline $\mathrm{I}_{\mathrm{CaL}} \downarrow$ & SQT4 & CACNA1C & Cav1.2 & Loss & & Shortened & $A F, V T, V F$ & 121,122 \\
\hline $\mathrm{I}_{\mathrm{CaL}} \uparrow$ & LQT8 & CACNA1C & Cav1.2 & Gain & $\begin{array}{l}\text { BAY K8644 } \\
\text { FPL64176 }\end{array}$ & Lengthened & $\mathrm{TdP}$ & $34,123,124$ \\
\hline
\end{tabular}

$\overline{\mathbf{A F}}=$ atrial fibrillation; $\mathbf{A P D}=$ action potential duration; $\mathbf{h E R G}=$ human ether-à-go-go subunit; $\mathbf{I}_{\mathbf{C a L}}=\mathrm{L}$-type calcium current; $\mathbf{I}_{\mathbf{K r}}=$ rapid delayedrectifier potassium current; $\mathbf{I}_{\mathbf{K s}}=$ slow delayed-rectifier potassium current; $\mathbf{I}_{\mathbf{N a}}=$ sodium current; $\mathbf{L Q T}=$ long $\mathbf{Q T}$; $\mathbf{S Q T}=$ short $\mathbf{Q T}$; TdP= torsades de pointes; VF=ventricular fibrillation; VT=ventricular tachycardia; $\uparrow$ indicates increased; $\downarrow$ indicates decreased.

It is important to validate the efficiency of various models for proarrhythmic risk-profiling. Sensitivity expresses how well a model recognizes drugs that can be proarrhythmic in humans. A highly sensitive model may effectively filter drugs that can be clinically harmful, but it may also produce false-positive results that stop the development of potentially useful proarrhythmia-free agents. Thus, an additional important indicator is the specificity, which is a measure of how often drugs identified as potentially proarrhythmic truly have proarrhythmic risk. A reliable proarrhythmia model requires validation showing that it has sufficient sensitivity and specificity for proarrhythmia screening.

Most pharmaceutical companies conduct cardiovascular safety studies (frontloading) before selection of candidate drugs for development. ${ }^{[147]}$ Surveyed pharmaceutical companies reported the use of hERG assays, isolated organ studies, APD measurements and in vivo QT interval measurements in $100 \%, 48 \%, 62 \%$ and $83 \%$ of drug development screening programmes, respectively. ${ }^{[147]}$ Regulatory guidelines do not yet contain recommendations for testing liability to drug-induced proarrhythmia forms other than
LQTS (e.g. drug-induced Brugada syndrome and SQTS). Eventually, new assays and models will need to be developed and standardized for these paradigms. Table IV summarizes the advantages and disadvantages of the available preclinical models for TdP risk assessment.

\section{1 In Silico Modelling}

Several in silico techniques are in development for use in drug discovery. In silico approaches include ligand-based modelling, target-based modelling (e.g. structural modelling of potential interactions with hERG and other ion channels) and electrophysiological modelling of single cells or even whole hearts. ${ }^{[148-150]}$ An in silico hERG modelling study reported impressive prediction of blocking effects for a test set of 28 compounds, with a sensitivity, specificity and accuracy of $90 \%, 86 \%$ and $89 \%$, respectively. ${ }^{[151]}$ In addition, in silico models of adverse reactions and understanding of receptor systems are valuable tools for early compound profiling. ${ }^{[152]}$ In silico analysis has provided insights into the impact of serum ion-level changes during haemodialysis on drug-induced APD prolongation with potential 
impact on arrhythmias. ${ }^{[153]}$ In silico modelling has also provided insights regarding the response to flecainide and mexiletine administration in congenital LQT3 and Brugada syndrome patients. ${ }^{[54]}$ Despite the usefulness of in silico modelling, a recently reported study indicated that only $37 \%$ of the 54 companies surveyed are using this method to predict ion channel/hERG channel interactions. ${ }^{[147]}$ The in silico screens will clearly not eliminate the necessity for in vitro and in vivo screening methods in the near future. However, the rational application of in silico methods during early discovery phases may allow for more cost- and resource-efficient design of candidate drugs with improved safety profiles. ${ }^{[151]}$

\subsection{In Vitro Models}

A variety of in vitro animal models are used to assess potential cardiac electrophysiological and proarrhythmic effects. Effects can be studied at levels ranging from ionic currents through arrhythmia development in systems varying from single cell models to complex organ preparations. Generally, tests in simpler systems are less expensive and provide larger throughput, and are therefore useful for initial screening. More complex procedures are eventually needed for compounds that pass initial screening and are taken to further stages of development, or compounds with particularly important clinical potential selected despite early positive signals.

Table III. Risk contributors that enhance sensitivity of preclinical assays

\begin{tabular}{|c|c|c|}
\hline$\overline{\text { Assay }}$ & Risk contributors & References \\
\hline$\overline{\text { APD }}$ & $\begin{array}{l}\text { Limited repolarization reserve (Purkinje fibre) } \\
\text { Bradycardia (long cycle length) } \\
\text { Female gender } \\
\text { Hypokalaemia }\end{array}$ & 138 \\
\hline Wedge & $\begin{array}{l}\text { Bradycardia } \\
\text { Female gender } \\
\text { Hypokalaemia } \\
\text { Hypomagnesaemia } \\
\text { Autonomic stimulation } \\
\text { Pacing algorithms } \\
\text { Drug-induced weakening of repolarization reserve }\end{array}$ & $139-141$ \\
\hline Langendorff heart (SCREENIT) & $\begin{array}{l}\text { Bradycardia } \\
\text { AV block + pace } \\
\text { AV block + escape rhythm } \\
\text { Hypokalaemia } \\
\text { Hypomagnesaemia } \\
\text { Female gender } \\
\text { Autonomic stimulation } \\
\text { Pacing algorithms (mimic SLS sequence) }\end{array}$ & 35,142 \\
\hline In vivo rabbit & $\begin{array}{l}\text { Bradycardia } \\
\text { Hypokalaemia } \\
\text { Female gender } \\
\text { Anaesthesia }\end{array}$ & $15,86,143$ \\
\hline AV block, canine & $\begin{array}{l}\text { Anaesthesia (halothane, isoflurane, pentobarbitone) } \\
\text { Hypertrophy } \\
\text { Electrical remodelling (decreased repolarization reserve) } \\
\text { Hypokalaemia } \\
\text { Pacing algorithms (mimic SLS sequence) }\end{array}$ & 12,144 \\
\hline Failing rabbit heart & $\begin{array}{l}\text { Hypertrophy } \\
\text { Heart failure } \\
\text { Electrical remodelling (decreased repolarization reserve) }\end{array}$ & 36 \\
\hline Telemetry & $\begin{array}{l}\text { Hypokalaemia } \\
\text { Female gender }\end{array}$ & 145,146 \\
\hline
\end{tabular}


Table IV. Advantages and disadvantages of long QT syndrome-liability screens and measurable proarrhythmia parameters

\begin{tabular}{|c|c|c|c|}
\hline Assay & Advantages & Disadvantages & Proarrhythmia parameters \\
\hline$\overline{h E R G^{a}}$ & $\begin{array}{l}\text { Less expensive } \\
\text { High throughput } \\
\text { Automated } \\
\text { Low technical challenge }\end{array}$ & $\begin{array}{l}\text { Inter-laboratory variability } \\
\text { Not able to give information about } \\
\text { additional channel inhibition } \\
\text { Moderate specificity } \\
\text { Moderate sensitivity }\end{array}$ & hERG current \\
\hline $\mathrm{APD}^{\mathrm{a}}$ & $\begin{array}{l}\text { Low cost } \\
\text { High sensitivity } \\
\text { Frequency dependency detectable } \\
\text { Easily accessible }\end{array}$ & $\begin{array}{l}\text { Species-specific current } \\
\text { expression affects applicability to } \\
\text { humans } \\
\text { Moderate specificity } \\
\text { Purkinje fibres may not respond to } \\
\mathrm{I}_{\mathrm{Ks}} \text { blockers (false negative } \\
\text { response) }\end{array}$ & $\begin{array}{l}\text { APD } \\
\text { EADs } \\
\text { DADs } \\
\text { Triangulation } \\
\text { Reverse use-dependence }\end{array}$ \\
\hline Wedge $^{a}$ & $\begin{array}{l}\text { Simultaneous AP and ECG } \\
\text { Direct determination of TDR } \\
\text { (recordings from the three layers) } \\
\text { High sensitivity } \\
\text { High specificity } \\
\text { Can detect proarrhythmia related to } \\
\mathrm{I}_{\mathrm{Na}} \text { and short QT syndrome }\end{array}$ & $\begin{array}{l}\text { Low throughput } \\
\text { High technical challenge }\end{array}$ & $\begin{array}{l}\text { Dispersion } \\
\text { EAD } \\
\text { DAD } \\
\text { ECG (QRS, QT, TpTe) } \\
\text { R on T } \\
\text { TdP like VT } \\
\text { ICF }\end{array}$ \\
\hline $\begin{array}{l}\text { Langendorff heart }^{\text {a }} \\
\text { (SCREENIT) }\end{array}$ & $\begin{array}{l}\text { Low cost } \\
\text { High variety of proarrhythmic } \\
\text { parameters } \\
\text { Frequency depending effect } \\
\text { High sensitivity } \\
\text { High specificity } \\
\text { High reproducibility } \\
\text { Well validated (SCREENIT) }\end{array}$ & $\begin{array}{l}\text { Less validated } \\
\text { Difficult interlaboratory comparison } \\
\text { (different modified setups and } \\
\text { protocols) } \\
\text { Expensive (SCREENIT) } \\
\text { Moderate technical challenge } \\
\text { (SCREENIT) }\end{array}$ & $\begin{array}{l}\text { MAPD } \\
\text { EAD } \\
\text { DAD } \\
\text { Triangulation } \\
\text { Reverse use-dependence } \\
\text { ECG (PQ, QT, QRS, RR, } \\
\text { TpTe) } \\
\text { BVR } \\
\text { VPB } \\
\text { R on T } \\
\text { TdP }\end{array}$ \\
\hline In vivo rabbit ${ }^{\mathrm{b}}$ & $\begin{array}{l}\text { Simple } \\
\text { Moderate throughput } \\
\text { PK/PD effects } \\
\text { Chronic drug administration } \\
\text { feasible } \\
\text { High reproducibility } \\
\text { High success rate } \\
\text { High specificity } \\
\text { Inexpensive }\end{array}$ & $\begin{array}{l}\text { Mechanism of } \alpha_{1} \text {-adrenoceptor } \\
\text { facilitation is unknown } \\
\text { Drug action on } \alpha_{1} \text {-adrenoceptor } \\
\text { complicates analysis of results } \\
\text { Moderate sensitivity (requires large } \\
\text { amount of drug) } \\
\text { Less validated }\end{array}$ & $\begin{array}{l}\text { ECG (PQ, QRS, QT, RR) } \\
\text { BVR } \\
\text { VPB } \\
\text { R on T } \\
\text { TdP }\end{array}$ \\
\hline $\begin{array}{l}\text { AV block, canine } \\
(\text { rabbit and monkey })^{\mathrm{b}}\end{array}$ & $\begin{array}{l}\text { Mimics diseased heart } \\
\text { PK/PD effects } \\
\text { Chronic drug administration } \\
\text { feasible } \\
\text { High reproducibility } \\
\text { High specificity }\end{array}$ & $\begin{array}{l}\text { High technical challenge } \\
\text { Moderate success rate } \\
\text { Low throughput } \\
\text { Expensive } \\
\text { Requires large amount of drug } \\
\text { Less validated }\end{array}$ & $\begin{array}{l}\text { MAPD } \\
\text { EAD } \\
\text { DAD } \\
\text { Dispersion } \\
\text { ECG (QRS, QT, TpTe) } \\
\text { BVR } \\
\text { VPB } \\
\text { R on T } \\
\text { TdP }\end{array}$ \\
\hline Failing rabbit heart $^{\mathrm{b}}$ & $\begin{array}{l}\text { High success rate } \\
\text { Mimics diseased heart }\end{array}$ & $\begin{array}{l}\text { High technical challenge } \\
\text { Less validated } \\
\text { Low throughput }\end{array}$ & $\begin{array}{l}\text { ECG (PQ, QRS, QT, RR) } \\
\text { BVR } \\
\text { VPB } \\
\text { R on T } \\
\text { TdP }\end{array}$ \\
\hline
\end{tabular}


Table IV. Contd

\begin{tabular}{|c|c|c|c|}
\hline Assay & Advantages & Disadvantages & Proarrhythmia parameters \\
\hline Conscious telemetry $^{\mathrm{b}}$ & $\begin{array}{l}\text { Similar electrophysiology to the } \\
\text { human } \\
\text { No drug interaction } \\
\text { No TdP-VF transition (monkey) }\end{array}$ & $\begin{array}{l}\text { Low sensitivity } \\
\text { Less proarrhythmic parameters } \\
\text { Less validated }\end{array}$ & $\begin{array}{l}\text { ECG (PQ, QRS, QT, RR) } \\
\text { BVR } \\
\text { VPB } \\
\text { R on T } \\
\text { TdP }\end{array}$ \\
\hline \multirow{2}{*}{\multicolumn{4}{|c|}{$\begin{array}{l}\text { a Not able to inform about the effects of plasma protein binding, the effects of metabolites, effects of chronic } \\
\text { hormonal influences. } \\
\text { b Able to provide PK/PD information (i.e. dose-proarrhythmia curve, drug metabolism, drug-interaction). }\end{array}$}} \\
\hline & & & \\
\hline \multicolumn{4}{|c|}{$\begin{array}{l}\mathbf{A P}=\text { action potential; } \mathbf{A P D}=\mathrm{AP} \text { duration; } \mathbf{B V R}=\text { beat-to-beat variability of repolarization; } \mathbf{D A D}=\text { delayed afterdepolarization; } \mathbf{E A D}=\text { early } \\
\text { afterdepolarization; } \mathbf{h E R G}=\text { human ether-à-go-go; } \mathbf{I C F}=\text { isometric contractile force; } \mathbf{I}_{\mathbf{K s}}=\text { slow delayed-rectifier potassium current; } \mathbf{I}_{\mathbf{N a}}= \\
\text { sodium current; } \mathbf{M A P D}=\text { monophasic action potential duration; } \mathbf{P D}=\text { pharmacodynamics; } \mathbf{P K}=\text { pharmacokinetics; } \mathbf{T d P}=\text { torsades de pointes; } \\
\text { TDR = transmural dispersion of repolarization; } \mathbf{T p T e}=\text { interval between the peak and the end of the ECG } \mathrm{T} \text { wave; } \mathbf{V F}=\text { ventricular fibrillation; } \\
\text { VPB = ventricular premature beat; } \mathbf{V T}=\text { ventricular tachycardia. }\end{array}$} \\
\hline
\end{tabular}

Potential disadvantages of in vitro models relate to the fact that they exclude the effects of plasma protein binding, the effects of metabolites, effects of chronic drug exposure, and neuronal and hormonal influences. In vitro results can also be strongly influenced by certain physicochemical properties of test drugs (e.g. adsorption to glass or plastic surfaces, poor solubility), leading to reduced effective drug concentrations and decreasing sensitivity.

\subsubsection{Human Ether-à-Go-Go (hERG) Subunit Assay}

In virtually all cases of drug-induced TdP, culprit drugs inhibit the current carried by hERG $\left(\mathrm{I}_{\mathrm{hERG}}\right)$, the $\alpha$-subunit underlying $\mathrm{I}_{\mathrm{Kr}}{ }^{[155]}$ Therefore, screening with a hERG-blocking assay is very useful for identifying drugs that are likely to have proarrhythmic potential. However, drugs might affect additional cardiac ion channels, which can either diminish or enhance QTprolonging and proarrhythmic potential. Therefore, additional assays on cells, tissues or organs may provide valuable information about net effects on repolarization and TdP risk.

$\mathrm{I}_{\mathrm{hERG}} / \mathrm{I}_{\mathrm{Kr}}$ assays can be performed in freshly isolated cardiac ventricular myocytes or cell lines expressing hERG, with Chinese hamster ovary and human embryonic kidney cells being common choices. ${ }^{[156,157]}$ Blocking potency $\left(\mathrm{IC}_{50}\right.$, i.e. the concentration that produces $50 \%$ inhibition) can be assessed by standard manual electrophysiology, but is increasingly performed with automated patch-clamp methods. ${ }^{[157]}$ The cardio- myocyte system is the 'gold-standard', with more reliable and accurate results, but has low throughput and requires highly qualified human resources. ${ }^{[157]}$ In contrast, automated patchclamp methods provide very high throughput with less precise $\mathrm{IC}_{50}$ values. $\mathrm{IC}_{50}$ values for $\mathrm{I}_{\mathrm{hERG}}$ block can be influenced by experimental protocol (e.g. step vs ramp protocol) and temperature, ${ }^{[158,159]}$ extracellular $\mathrm{K}^{+}$concentration, ${ }^{[160,161]}$ pulse rate ${ }^{[162]}$ and solubility. Despite efforts to standardize hERG assays, there can be great variations in $\mathrm{IC}_{50}$ for a given drug among research labs. ${ }^{[61]}$

For drugs with multichannel blocking activity, the inhibition of $\mathrm{I}_{\mathrm{Na}}$ and/or $\mathrm{I}_{\mathrm{CaL}}$ may offset APD prolonging and proarrhythmic effects of $\mathrm{I}_{\mathrm{hERG}} / \mathrm{I}_{\mathrm{Kr}}$ block. The $\mathrm{I}_{\mathrm{CaL}}$ blocker verapamil (which has never been reported to cause TdP and can be therapeutic for long QT-related arrhythmias) inhibits $\mathrm{I}_{\mathrm{Kr}}$ in the same concentration range as quinidine and amiodarone. ${ }^{[163]}$ The antianginal agent ranolazine possesses multiple channel blocking properties, including $\mathrm{I}_{\mathrm{Kr}}$ inhibition, and suppresses EADs and TDR in canine perfused wedge preparations and in vivo models..$^{[164,165]}$ Thus, in some cases, reliance on hERG assays alone can lead to unnecessary rejection of potentially valuable compounds.

For drugs with weak $\mathrm{I}_{\mathrm{Kr}}$-blocking ability, safety margins should be considered, taking into account the $\mathrm{IC}_{50}$ and therapeutic free-drug plasma concentration. ${ }^{[61]}$ A hERG-blocking $\mathrm{IC}_{50}$ 30 -fold greater than the half-maximally effective 
unbound-drug concentration has been suggested to represent an adequate "cardiac safety index'. ${ }^{[166]}$ However, this rule is clearly not absolute, since verapamil is safe clinically despite a cardiac safety index of 1.7 (see above). ${ }^{[167]}$ It has also been suggested that a lower margin (10-fold) may be acceptable for drugs developed for lifethreatening conditions. ${ }^{[167]}$

Several drugs may lengthen QT intervals without directly blocking $\mathrm{I}_{\mathrm{hERG}}$, by inhibiting hERG trafficking to the plasma membrane. ${ }^{[168-170]}$ In such cases, hERG assays may provide falsenegative results. Recently, an antibody-based chemiluminescent assay called HERG-Lite ${ }^{\circledR}$ was developed and validated to accurately predict both channel blockers and trafficking inhibitors in a rapid, high-throughput, cost-effective manner. ${ }^{[171]}$

Rubidium efflux assay may provide highthroughput screening at relatively low cost, and yield quantitative information about hERGinhibiting potential, but rubidium may reduce $\mathrm{I}_{\mathrm{hERG}}$ inactivation, which decreases the sensitivity of the assay for the test drug. ${ }^{[172,173]}$ A new thallium flux assay was recently validated as an alternative method to profile large-volume compound libraries for hERG channel blocking activity. ${ }^{[174]}$ Human embryonic stem cell-derived cardiomyocyte assays are also presently under development. ${ }^{[175]}$

$\mathrm{I}_{\mathrm{hERG}}$ assays are able to detect hERG-current activators, and might therefore be useful in screening for drugs inducing SQTS. A recent study applied $\mathrm{I}_{\mathrm{hERG}}$ assays to screen $170 \mathrm{com}-$ pounds, showing high specificity (97\%) and moderate sensitivity (55\%) for hERG activators and moderate sensitivity (66\%) and specificity (59\%) for hERG blockers, with APD response assay as the 'gold standard'. [176]

Several hERG drug-binding sites have been identified, at which mutations (e.g. F656, Y652) decrease drug access to hERG. ${ }^{[177-179]}$ The use of $\mathrm{hERG}$ isoforms carrying such mutations can increase specificity at the cost of decreased sensitivity. Up to $40-86 \%$ of new chemical entities may inhibit hERG at high concentrations (i.e. up to the limit of solubility). ${ }^{[180]}$ Witchel ${ }^{[181]}$ estimated that $40-70 \%$ of new chemical entities have to be abandoned because of an inadequate window for hERG blockade. Additional tests may be required for compounds that pass hERG assay if a preclinical signal for QT prolongation or proarrhythmia is obtained, and some particularly promising drugs in challenging therapeutic areas may be subjected to further testing to assess proarrhythmic potential more deeply despite a positive signal on hERG assay.

\subsubsection{Purkinje Fibre and Papillary Muscle Action Potential Duration Assays}

One limitation of the hERG assay is that it predicts TdP risk for hERG-blocking drugs that have low proarrhythmic liability by virtue of inward current-blocking actions that antagonize the consequences of $\mathrm{I}_{\mathrm{Kr}}$-block. ${ }^{[182]}$ APD assays with fine-tipped microelectrodes in multicellular preparations provide precise information about drug-induced changes in the shape and duration of APs at varying stimulation rates. Guinea pig, rabbit or canine papillary muscle and Purkinje fibre APD assays are used most commonly in preclinical safety studies. ${ }^{[147]}$ APD recordings are easy to perform and plasma proteins can be added to the system to control for protein binding effects. ${ }^{[183]}$ Changes in AP shape are at least as important as changes in APD. A recent study showed that repolarization risk evaluation based on $\mathrm{APD}_{90}$ values detected two of six clinically positive compounds, whereas five of six compounds were detected based on AP triangulation. ${ }^{[184]}$ Purkinje fibre APD assessment may be superior for detecting proarrhythmic repolarization-delaying properties. ${ }^{[185]}$ The QT PRODACT project showed that guinea pig papillary muscle APD assay predicts QT interval prolongation in humans. ${ }^{[186]}$ However, APD assay is not predictive of all QT-prolonging drugs (e.g. terfenadine) ${ }^{[187]}$ does not reliably predict the torsadogenic potential of all drugs and has moderate throughput. APD assays, with their high sensitivity and moderate specificity, may therefore be of most value in clarifying incoherent results of ion channel studies, assessing drugs with multiple channel blocking ability or defining mechanisms of actions. ${ }^{[147]}$ 


\subsubsection{Arterially Perfused Wedge Preparations}

The isolated wedge preparation was introduced by Yan et al. ${ }^{[72,188]}$ Arterially perfused slabs of canine and rabbit myocardium are most frequently used in the model, which is suitable for recording endo-, midmyo- and epicardial APs simultaneously. ${ }^{[139]}$ Midmyocardial cell (M cell) APDs are believed to be important determinants of QT intervals and TdP arrhythmogenesis, ${ }^{[139]}$ although their precise role remains somewhat controversial. ${ }^{[189]}$ For instance, Voss et al. ${ }^{[190]}$ did not observe a midmyocardial zenith, either in vivo or in the wedge preparation, under physiological conditions, raising questions about the functional role of $\mathrm{M}$ cells. The $\mathrm{T}_{\text {peak }}-\mathrm{T}_{\text {end }}$ index (interval between peak and end of the $\mathrm{T}$ wave), which reflects TDR, ${ }^{[39,72]}$ may provide predictive information about TDP risk, and the pseudo-ECG shows proarrhythmic activity. ${ }^{[41]}$ However, Opthof et al. ${ }^{[191]}$ found that the $T_{\text {peak }}-T_{\text {end }}$ does not correlate with TDR in dogs in vivo, rather correlating with whole-heart repolarization. These findings question the application of aspects of wedge data to the in situ heart. Some drugs show qualitatively different effects on TDR at different concentrations (e.g. bell-shaped concentrationresponse), emphasizing the importance of assessing a wide range of concentrations. ${ }^{[65,157,192,193]}$

Wedge preparations can also suggest multichannel inhibition effects. For example, $\mathrm{I}_{\mathrm{Na}}$ and $\mathrm{I}_{\mathrm{CaL}}$-blocking actions may be reflected by reduced contractile force and $\Delta \mathrm{T}_{\text {peak }}-\mathrm{T}_{\text {end }} / \mathrm{QT}$ ratios (ratios $<10$ accompanied by QRS widening suggest combined block of $\mathrm{I}_{\mathrm{Kr}}$ and $\mathrm{I}_{\mathrm{Na}}$ ). ${ }^{[139]}$ Wedge preparations may also be useful in assessing proarrhythmic manifestations other than TdP, such as SQTS-related VT/VF risk as seen with pinacidil and PD-118057, ${ }^{[194,195]}$ and proarrhythmic consequences of $\mathrm{I}_{\mathrm{Na}}$ and $\mathrm{I}_{\mathrm{CaL}}$ blockade. ${ }^{[139,196,197]}$

A scoring index was recently developed to assess proarrhythmic risk by considering percentage change in QT interval, percentage change in $\Delta \mathrm{T}_{\text {peak }}-\mathrm{T}_{\text {end }} / \mathrm{QT}$ ratio, and the incidence of EADs with or without R-on-T extrasystoles and TdP. ${ }^{[65,139,198,199]}$ Although the ventricular wedge preparation model has been validated, it has low throughput and requires complex technical skills. ${ }^{[63]}$ Recent papers have reported high success rates. ${ }^{[139,200]}$

\subsubsection{Langendorff-Perfused Rabbit Hearts}

The retrogradely perfused Langendorff AVablated rabbit heart model is one of the most frequently used preclinical testing methods. Many drugs have been tested in the fully automated SCREENIT ${ }^{\circledR}$ system introduced by Hondeghem et al. ${ }^{[45]}$ Epi- and endocardial monophasic APs (MAPs) are recorded and proarrhythmic potential characterized by indexes such as EADs, VT/VF ${ }^{[201]}$ and TRIaD. ${ }^{[25]}$ The TRIaD concept was introduced by Hondeghem et al., ${ }^{[25,45]}$ and stands for: AP Triangulation (prolongation of $\mathrm{APD}_{30-90}$ ), Reverse use dependence, AP Instability and Dispersion. The use of TRIaD in SCREENIT correctly identified proarrhythmic agents of various mechanisms, even those having small margins between the hERG $\mathrm{IC}_{50}$ and predicted maximum effective free therapeutic plasma concentration. ${ }^{62,202]}$ TRIaD also predicted proarrhythmic propensity of 26 drug candidates in a recently published isolated guinea pig proarrhythmia model.[203] Although SCREENIT accurately discriminates proarrhythmic from non-proarrhythmic drugs, proarrhythmic drug concentrations are sometimes inconsistent. ${ }^{[201,202,204]}$ Lawrence et al. ${ }^{[62]}$ found that SCREENIT can predict clinical outcome, particularly for drugs with very high or very low torsadogenic potential. However, two or three false-negative results were found in a study of TdP liability for 55 compounds. ${ }^{[167]}$ SCREENIT can be useful for testing drugs at concentrations similar to $\mathrm{IC}_{50}$ values from $\mathrm{hERG}$ assays before committing to more costly in vivo QTc experiments (e.g. ECG telemetry in dogs and monkeys). ${ }^{[205]}$ The relationship between TRIaDrisk drug concentrations and clinical concentrations is likely to be an important index, since many drugs can produce at-risk TRIaD indexes at high enough concentrations. ${ }^{[206]}$

A variety of other isolated heart models involving AV block and different perfusion buffers have been used to assess TdP liability. ${ }^{[35,207-210]}$ Pacing sites need to be chosen with caution to avoid pacing-induced arrhythmias. ${ }^{[211,212]}$ In 
hearts with intact AV conduction, susceptibility to drug-induced arrhythmia is reduced, owing to more regular and higher heart rates. ${ }^{[10]}$ Thus, larger concentrations of drugs are needed to evoke proarrhythmia compared with AVblocked hearts and predictive value is reduced.

Dynamic ECG parameters such as beat-to-beat variability of ventricular repolarization (BVR) of QT intervals (short-term variability [STV]; total instability) were suggested to determine proarrhythmic outcome in an in vivo dog proarrhythmia model. ${ }^{[46,83]}$ In one study, dofetilide increased all QT variability parameters (an example of typical dofetilide effects is shown in figure 2); however, neither verapamil nor lidocaine decrease QT variability parameters, while both prevent $\mathrm{TdP}$ in isolated rabbit hearts. ${ }^{[35]}$ Most TdP events are preceded by simple arrhythmias (i.e. VPBs, salvoes of ventricular beats, bigeminy, etc.), which increase in number and produce large beat-to-beat irregularity and instability before TdP. Instability may remain latent until the appearance of VPBs. ${ }^{[47]}$ Since TdP is preceded by simple arrhythmias and associated increased cycle length variation, the use of dynamic ECG BVR in preclinical studies merits further assessment as a predictive quantitative index.

The most complex in vitro models are the Langendorff perfused heart models with moderate throughput and high success rate. ${ }^{[63]}$ The SCREENIT model is a well studied, reproducible, robust and validated preclinical model with high sensitivity and specificity that provides many parameters relevant to proarrhythmia testing. ${ }^{[62,201,202,204,205]}$ However, all in vitro models lack crucial elements seen in vivo, such as metabolite effects and neurohormonal influences. Furthermore, all models in normal hearts may fail to inform about TdP risks specific to diseased hearts, in which proarrhythmia more commonly occurs. SCREENIT requires a commercial license, which limits its widespread use. Modified, manual-method Langendorff models are licensefree and easily available, but less well validated.

\subsection{In Vivo TdP Models}

In vivo proarrhythmia models are more complex than in vitro models, but provide a wide

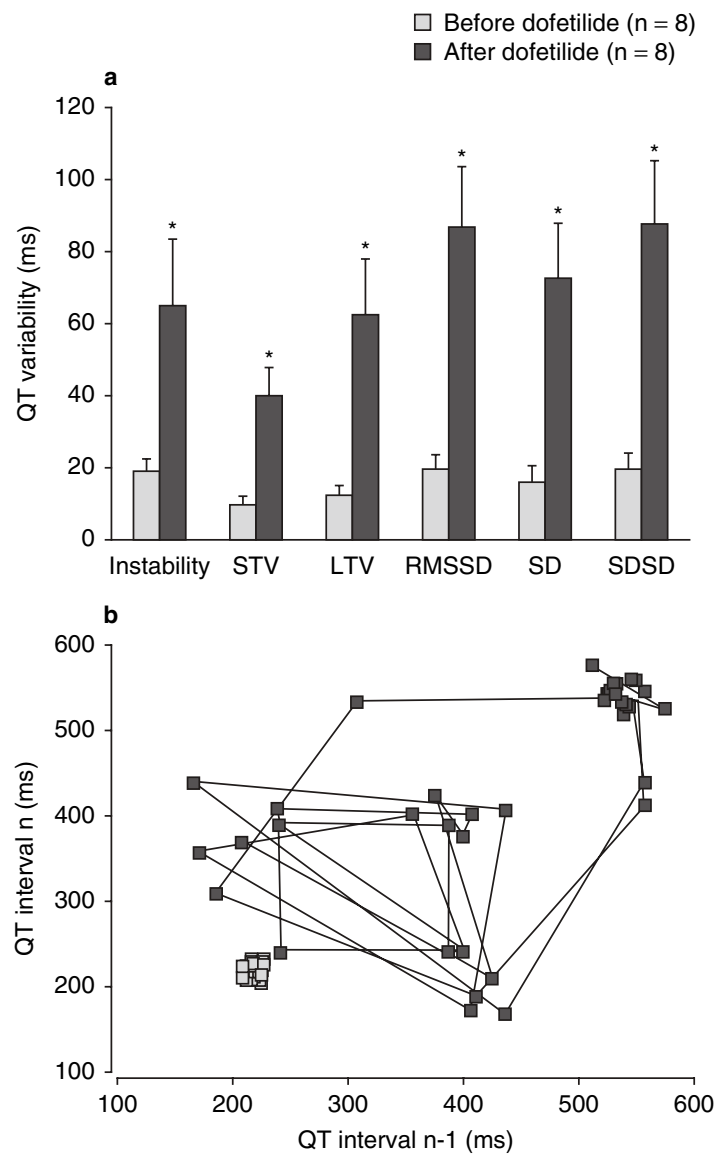

Fig. 2. Beat-to-beat $Q T$ variability parameters in isolated atrioventricular-ablated rabbit hearts exposed to dofetilide. (a) Beat-to-beat QT variability parameters before and after dofetilide administration. (b) A representative Poincaré plot of an experiment before and after dofetilide administration, showing the relationship of successive QT intervals to each other. Under control conditions, values are clustered together, showing little variation. After dofetilide, there is substantially increased variability, with many data points indicating alternating long and short QT sequences typifying QT alternans. LTV = long-term variability; RMSSD = root mean square of successive QT differences; $\mathbf{S D}=$ standard deviation of $\mathrm{QT}$ intervals; SDSD = standard deviation of successive QT differences; STV = short-term variability. ${ }^{*} p<0.05$.

variety of information about drug pharmacodynamics and pharmacokinetics. They are particularly suitable for assessing drugs already suspected of proarrhythmic risk based on in vitro studies. In the absence of valid, highly sensitive and specific surrogate parameters, ICH 7SB recommends QT response assays. 


\subsection{In Vivo Studies in Normal Animals}

\section{$\alpha_{1}$-Adrenoceptor-Sensitized Anaesthetized} Rabbit Model

The $\alpha_{1}$-adrenoceptor-sensitized anaesthetized rabbit model of acquired LQTS developed by Carlsson et al. ${ }^{[143]}$ is one of the most commonly used animal models for in vivo QT prolongation/proarrhythmia screening. In this model, the TdP liability of a test agent is evaluated during co-administration of a 'priming' substance - the selective $\alpha_{1}$-adrenoceptor agonist methoxamine $^{[143]}$ or phenylephrine. ${ }^{[213-215]}$

The role of the $\alpha_{1}$-stimulation in this model is still unclear. $\alpha_{1}$-Agonists may affect potassium currents: methoxamine inhibits transient outward potassium current $\left(\mathrm{I}_{\mathrm{to}}\right)$ and prolongs APD in rat ventricular and rabbit atrial cells $(100 \mu \mathrm{mol} / \mathrm{L})$, inhibits $\mathrm{I}_{\mathrm{K}}$ and prolongs APD in canine Purkinje fibres $(0.1-10 \mu \mathrm{mol} / \mathrm{L})$ and inhibits inward rectifier potassium current $\left(\mathrm{I}_{\mathrm{K} 1}\right)$ in canine Purkinje fibres and rabbit ventricular cells $(0.01-1 \mathrm{mmol} / \mathrm{L})$. ${ }^{[216-219]}$ $\alpha_{1}$-Adrenoceptor stimulation increases intracellular $\mathrm{Ca}^{2+}$ concentration $\left(\left[\mathrm{Ca}^{2+}\right]_{\mathrm{i}}\right)$ via the $\mathrm{G}_{\mathrm{i}}-\mathrm{IP} 3 /$ DAG-PKC pathway (where IP3 is inositol 1,4,5 triphosphate, DAG is diacyclglycerol and PKC is protein kinase C). ${ }^{[220]}$ Increased $\left[\mathrm{Ca}^{2+}\right]_{\mathrm{i}}$ can lead to triggered activity and $\mathrm{TdP} \cdot{ }^{[15]} \mathrm{A}$ role of $\left[\mathrm{Ca}^{2+}\right]_{\mathrm{i}}$ is supported by the response to nisoldipine $\left(\mathrm{I}_{\mathrm{CaL}}\right.$ inhibitor) and flunarazine $\left(\mathrm{a}\left[\mathrm{Ca}^{2+}\right]_{\mathrm{i}}\right.$ overload blocker), which dose-dependently prevent TdP without attenuating the QT prolongation induced by almokalant, an $\mathrm{I}_{\mathrm{Kr}}$ blocker. ${ }^{[21]}$ Increased afterload due to $\alpha$-adrenergic stimulation may also increase ventricular stretch. However, neither stretch nor $\alpha_{1}$-adrenoceptor stimulation, nor their combination, enhance dofetilide-induced TdP in isolated rabbit hearts, suggesting that extracardiac $\alpha_{1}$-adrenoceptor-linked mechanisms may play an important role. ${ }^{[10]}$ Reflex bradycardia could be involved. ${ }^{[15]}$ However, Wang et al. ${ }^{[222]}$ found that prazosin pretreatment prevented hypertensive and bradycardic effects of phenylephrine, but did not prevent $\mathrm{TdP}$ induction by a late $\mathrm{I}_{\mathrm{Na}}$ activator. The autonomic nervous system per se plays a significant role in arrhythmogenesis. ${ }^{[101]}$ Sympathetic stimulation increases TDR in LQT1-2.[105] Bilateral vagotomy prevents clofilium-induced
TdP, suggesting an important contribution of parasympathetic tone. ${ }^{[111]}$ Baroreceptor sensitivity (BRS), an indicator of parasympathetic nervous system function, is increased in animals that develop dofetilide-induced TdP (unpublished data).

QT measurement in the in vivo rabbit can be difficult because of very short diastolic periods; therefore, extrapolation techniques are often used. ${ }^{[223]}$ Carlsson et al. ${ }^{[79]}$ found recently that STV predicts $\mathrm{TdP}$ in methoxamine-sensitized anaesthetized rabbits. However, other investigators have reported that neither QTc, QT BVR nor AP triangulation adequately predict TdP. ${ }^{[86,111]}$ Similarly, Michael et al. ${ }^{[106,119]}$ found that STV fails to predict TdP in phenylephrine-sensitized or adrenaline-sensitized anaesthetized guinea pigs. This model successfully identifies the proarrhythmia liability of numerous antiarrhythmic drugs, ${ }^{[15]}$ but is insensitive to quinidine $e^{[22,225]}$ and terfenadine. ${ }^{[225]}$ Since this proarrhythmia model requires the sensitizing effect of $\alpha_{1}$-adrenoceptor stimulation, the proarrhythmic potential of $\mathrm{I}_{\mathrm{Kr}}$-blocking drugs with ancillary $\alpha_{1}$-adrenoceptor blocking actions (i.e. quinidine, cisapride, etc.) may be underestimated. ${ }^{[15]}$ Additionally, the incidence of proarrhythmia depends on the anaesthetics used. ${ }^{[86]}$ These results urge caution in assessing the proarrhythmia liability of a test drug during $\alpha_{1}$-sensitization. Overall, this is a relatively simple, reproducible, moderate throughput model with a high success rate that is a useful complement to other proarrhythmia models, but is not a useful primary screen.

\section{Conscious ECG Telemetry in Dogs and Monkeys}

Technical development has made it possible to obtain long-term ECG recordings on conscious animals. Conscious guinea pig, dog and monkey ECG telemetry models have been developed. ${ }^{[145,146,226-228]}$ Beagle dogs and rhesus monkeys exhibit low inherent intra-animal variability and high sensitivity, allowing for the detection of small but potentially significant increases in QT/QTc intervals in the range of therapeutic plasma concentrations. ${ }^{[227,228]}$ Recently, in vivo QT assays in conscious cynomolgus monkeys have also been used to assess the risk of 
drug-induced QT interval prolongation. ${ }^{[146]}$ Champeroux et al. ${ }^{[91]}$ reported that the simple QT/RR relationship method determined by ECG telemetry provided a direct assessment of a druginduced effect on QT interval, without any curve fitting or application of correction formulae in conscious beagle dogs and cynomolgus monkeys. These models are reproducible and useful to evaluate in vivo QT prolongation, but usually they are considered less sensitive for TdP risk due to the absence of risk factors per se. The sensitivity for QT prolongation can be increased by a subject-specific QT correction factor. ${ }^{[228]}$

Slow Delayed-Rectifier Potassium Current-Inhibited Anaesthetized Rabbit and Canine Models

Lengyel et al. ${ }^{[80]}$ found that neither $\mathrm{I}_{\mathrm{Kr}}$ nor $\mathrm{I}_{\mathrm{Ks}}$ blockade increase the ECG beat-to-beat QT STV, and cause TdP with a low incidence, but STV and the incidence of TdP increase with a combination of $\mathrm{I}_{\mathrm{Kr}}$ and $\mathrm{I}_{\mathrm{Ks}}$ blockers. Decreased repolarization reserve with an $\mathrm{I}_{\mathrm{Ks}}$ blocker renders animals more susceptible to $\mathrm{TdP}$, which may be useful for drug testing.

Acquired LQT1 with TdP occurs following the administration of isoproterenol in $\mathrm{I}_{\mathrm{Ks}}$-inhibited anaesthetized beagle dogs. ${ }^{[29]}$ Anaesthesia can interfere with acquired LQTS development, but the fentanyl-etomidate combination provides comparable baseline values with conscious telemetered beagle dogs, ${ }^{[94]}$ making it useful for routine cardiovascular safety studies as well as the investigation of risk biomarkers. ${ }^{\left[{ }^{[3,229]}\right.}$ The use of $\mathrm{I}_{\mathrm{Ks}}$-blockade to mimic the reduced repolarization reserve commonly predisposing to $\mathrm{TdP}$ in humans is an interesting approach to obtaining clinically relevant TdP risk data, but more experience and precise validation of this method are needed.

\subsubsection{Pathological In Vivo TdP Models}

An increasing number of experimental models have been established with electrical (APD prolongation associated with decreased outward repolarizing currents) and structural (ventricular dilation, hypertrophy, fibrosis) remodelling, mimicking the clinical circumstances under which TdP most commonly occurs. For example, electrical remodelling of the failing myocardium causes downregulation of $\mathrm{I}_{\mathrm{Kr}}, \mathrm{I}_{\mathrm{Ks}}, \mathrm{I}_{\mathrm{to}}$ [12,230-232] and $\mathrm{I}_{\mathrm{CaL}}{ }^{[233]}$ and upregulation of NCX current, ${ }^{[12]}$ and heart failure is a risk factor for TdP. A decrease in repolarization reserve $\mathrm{e}^{[155,234]}$ and abnormal $\mathrm{Ca}^{2+}$ handling ${ }^{[235]}$ predispose such animals to drug-induced TdP. ${ }^{[12,236-238]}$

\section{Chronic Atrioventricular-Block Animal Models}

The chronic AV block (CAVB) dog TdP model was established more than a decade ago. ${ }^{[144]}$ Since then, it has become one of the most frequently used in vivo TdP screening models, probably second only to the $\alpha_{1}$-adrenergicstimulated rabbit TdP model.

The bradycardia caused by AV block leads to volume overload, resulting in increased ventricular wall strain and diastolic stress. ${ }^{[239-241]}$ The serum levels of several stress-sensitive hormones increase, including noradrenaline (norepinephrine), angiotensin II, and atrial and brain natriuretic peptides. ${ }^{[12]}$ Haemodynamic and electrical remodelling develop rapidly and are followed by slower structural remodelling, with left ventricular hypertrophy evolving over 4-6 weeks. ${ }^{[12,60]}$ Remodelling lengthens APD and promotes triggered activity. Interestingly, hypertrophy does not appear to be a prerequisite for electrical remodelling or druginduced TdP in this model. ${ }^{[242]}$

Increased resting $\left[\mathrm{Ca}^{2+}\right]_{i}$ and spontaneous sarcoplasmic $\mathrm{Ca}^{2+}$ release occur in CAVB cardiomyocytes ${ }^{[243]}$ and are likely to play a role in triggered arrhythmias. Transient inward current $\left(\mathrm{I}_{\mathrm{ti}}\right.$; carried mainly by enhanced NCX activity) can generate delayed afterdepolarizations. ${ }^{[235]}$

In the canine CAVB model, the incidence of arrhythmias is lower in conscious than in anaesthetized animals. Vos and colleagues, ${ }^{[12]}$ who developed the model, generally use a combination of pentobarbitone (pentobarbital) and halothane or isoflurane. These agents are known to have direct electrophysiological actions, blocking $\mathrm{K}^{+}$-currents and decreasing repolarization reserve, bringing the predisposed CAVB phenotype closer to the proarrhythmic threshold. ${ }^{[244-246]}$

$\mathrm{TdP}$ is produced in $>70 \%$ of CAVB dogs upon exposure to $\mathrm{I}_{\mathrm{Kr}}$ blockers associated with druginduced LQTS, such as dofetilide, azimilide and almokalant. ${ }^{[12]}$ Following validation with both 
proarrhythmic and non-proarrhythmic drugs, the CAVB dog model is now considered suitably reproducible and sensitive for new-drug evaluation. ${ }^{[12,60]}$ However, only $65-70 \%$ of CAVB dogs are drug-susceptible and can be used for testing, which is a nontrivial limitation. ${ }^{[12]}$

Tsuji et al. ${ }^{[232]}$ reported that CAVB, bradypaced rabbits are at high risk of spontaneous TdP. $\mathrm{CAVB} /$ bradypacing causes remodelling of ionchannel function, particularly $\mathrm{I}_{\mathrm{Ks}}$ and $\mathrm{I}_{\mathrm{Kr}}$ downregulation. Tachypaced rabbits also develop heart failure and ionic-current remodelling, with downregulation of $\mathrm{I}_{\mathrm{Ks}}$ but not $\mathrm{I}_{\mathrm{Kr}}$, and show isolated ventricular ectopy but not TdP. ${ }^{[232]}$ However, dofetilide administration reveals impaired repolarization reserve and induces $\mathrm{TdP}$ in tachypaced rabbits. The tachypaced CAVB rabbit model may thus be suitable for proarrhythmia testing, since spontaneous TdP does not occur, and decreased repolarization reserve produces a high likelihood of TdP with $\mathrm{I}_{\mathrm{Kr}}$ blockade. In addition to $\mathrm{K}^{+}$-channel downregulation and APD prolongation, $\mathrm{Ca}^{2+}$-handling abnormalities causing increased cell $\mathrm{Ca}^{2+}$ loading and $\mathrm{Ca}^{2+}$-calmodulin-dependent protein kinase II activation appear to play an important role in EAD generation and arrhythmogenesis in this model. ${ }^{[247]}$

Recently, a CAVB monkey model was introduced by Satoh et al. ${ }^{[248]}$ This system may have significant advantages over previous TdP models, both because of the phylogenetic similarity to humans and because TdP almost always terminates spontaneously, limiting collateral mortality. The low mortality rate allows for the comparison of multiple drugs in individual animals; furthermore, experiments with monkeys require smaller amounts of drugs, because of their small size ${ }^{[249]}$ and specific properties of metabolism by cytochrome P450 (CYP) 3A4. ${ }^{[250]}$

The CAVB models have low throughput compared with other preclinical assays, demand high technical skills and require further validation before more widespread use in proarrhythmia safety studies.

Failing Rabbit Hearts

Kijtawornrat and colleagues ${ }^{[36,251]}$ introduced a TdP model in rabbits with myocardial infarc- tion-induced heart failure. Heart failure rabbits developed TdP in greater number than normal rabbits after the administration of dofetilide, clofilium and cisapride. Increased temporal dispersion and abnormal $\mathrm{Ca}^{2+}$ cycling were thought to contribute to the TdP predisposition. ${ }^{[36,251]}$ Cardiomyocytes from the ischaemic area showed increased $\mathrm{Ca}^{2+}$ spark frequency related to spontaneous $\mathrm{Ca}^{2+}$ release from the sarcoplasmic reticulum: $\mathrm{Ca}^{2+}$-release events can cause triggered activity that initiates TdP. ${ }^{[36,251]}$ This model requires further validation before wider use for proarrhythmia screening.

\section{Clinical Proarrhythmia Analysis}

\section{1 Clinical LQTS Biomarkers}

The next step after preclinical risk assessment is evaluation of clinical proarrhythmic potential. The development of TdP is often preceded by alternation in $\mathrm{T}$-wave morphology, i.e. T-wave alternans (TWA). ${ }^{67-69,252-254]}$ In a TdP predictor identification study in humans, TWA was found to be more common in patients with TdP. ${ }^{[255,256]}$ Shimizu and Antzelevitch ${ }^{[25]}$ suggested that TWA at rapid rates under LQT conditions results from alternation in M-cell APD, leading to exaggeration of TDR. TWA also occurs in LQTS at relatively slower heart rates, at which TWA may be less likely. ${ }^{[70]}$ Shah and Hondeghem ${ }^{[25]}$ argued that AP instability is the experimental counterpart of TWA. Thus, TWA may provide information about increases in both the temporal and spatial dispersion of repolarization. The digital signal-processing counterpart of TWA, microvolt-level TWA, may detect subtle degrees of TWA and is also a broader marker of ventricular tachyarrhythmia vulnerability. ${ }^{[70]}$ However, Schmitt et al. ${ }^{[258]}$ found that in patients with congenital LQTS with a history of life-threatening arrhythmias but free of structural heart disease, microvolt-level TWA assessment does not provide additional prognostic information.

After STV was found to predict TdP in some experimental models, increased STV in QT parameters was observed in patients with both drug-induced and congenital LQTS. ${ }^{[81,82]}$ Berger 
substantial risk is detected. Shah ${ }^{[272]}$ suggested that a well designed ECG monitoring and QT concentration assessment as part of phase I clinical assessment may preclude a later TQTS; however, this idea remains to be considered by regulatory authorities.

The TQTS is considered negative when the upper bound of the $95 \%$ one-sided confidence interval for the time-matched effect of the drug on QTc excludes a $10 \mathrm{~ms}$ prolongation. Expanded ECG safety assessment may also be necessary in certain patient subgroups during later stages of drug development. ${ }^{[272]}$ Jonker et al. ${ }^{[273]}$ found in a pharmacokinetic-pharmacodynamic (PK/PD) model that $10 \%$ inhibition of hERG currents by dofetilide corresponds to $20 \mathrm{~ms}$ of QT interval prolongation in humans $(95 \% \mathrm{CI})$. This suggests that PK/PD modelling may predict the human QT response and provide useful information for integrated QT risk assessment.

Besides determining QT/QTc-prolonging potential of a test drug, the rate of arrhythmia (TdP, VT, VF) and adverse events (syncope, seizure, SCD) should be compared between treated and control patients. Because of the large sample sizes needed to detect rare but clinically significant arrhythmic events, postmarketing surveillance is important. Substantial QT/QTc interval prolongation during clinical development can be the basis for non-approval or discontinuation of an otherwise promising compound, even without proarrhythmia per se. Decisions about continuation of development and approval generally depend on the estimated proarrhythmic risk, the likely therapeutic benefit and the safety/efficacy of alternative therapies.

TQTS is quite sensitive for QT-prolonging proarrhythmic drugs, but its specificity is questionable. Verapamil, amiodarone and ranolazine are all examples of compounds that prolong the QT, but have little or no clinical proarrhythmic risk. ${ }^{[274]}$

\section{Detecting and Preventing Proarrhythmia in Clinical Practice}

Drug-induced TdP is relatively rare, but it is hard to estimate the occurrence rate precisely.
Many cases are not reported, definitive diagnosis requires ECG recording and other conditions can also lead to SCD (e.g. heart failure, cardiomyopathy). In addition, relative clinical TdP risk is difficult to quantify precisely for various drugs, because the intrinsic risk of the target population can differ greatly. For example, a drug given to patients with significant risk of cardiac damage and dysfunction, such as an antiarrhythmic, may for that reason alone be observed to cause TdP much more frequently than a drug commonly given to patients without heart disease, such as a macrolide antibacterial. Clinicians are ultimately responsible for the safety of the patients to whom they prescribe drugs, for proarrhythmia as well as other safety concerns. ${ }^{[275]}$ A silent gene mutation affecting cardiac repolarization has been detected in $10-40 \%$ of patients with acquired LQTS. ${ }^{[276,277]}$ Individuals who carry such asymptomatic mutations are at increased risk for TdP development when a potentially proarrhythmic drug is administered. The recognition of at-risk individuals is an important challenge. Future personalized medicine/genomic technologies may greatly facilitate recognition of patients with gene-variants predisposing them to TdP risk. In the meantime, awareness of the risk associated with potential QT-prolonging drugs and ECG verification after initiation of therapy are crucial.

Thus, clinicians must be aware of the doserelated proarrhythmic potential of various agents and of proarrhythmia risk factors (table VI). Female gender, structural heart disease, advanced age and coadministration of other potential QTprolonging agents are important risk factors. ${ }^{[314]}$ Even non-prescription drugs (e.g. antitussive agents) can increase TdP risk for patients taking other pharmaceutical preparations or having concomitant disease; therefore, caution is needed with unsupervised use of non-prescription medication. ${ }^{[303]}$ In addition, food and beverages may contain potentially proarrhythmic chemicals. Grapefruit juice containing naringenin inhibits the metabolism of several drugs such as the class III antiarrhythmics sotalol and amiodarone. ${ }^{[304]}$ The consumption of large amounts of grapefruit juice or tonic water containing quinine (optical isomer of quinidine) can be deadly in predisposed 
Table VI. Clinical risk factors for drug induced long-QT (LQT) syndrome

\begin{tabular}{|c|c|}
\hline Risk factors & References \\
\hline Age $>65$ years & 278 \\
\hline Female gender & 279 \\
\hline Cardiovascular diseases & 278 \\
\hline coronary artery disease & 280,281 \\
\hline ventricular hypertrophy & 282 \\
\hline dilated cardiomyopathy & 283 \\
\hline hypertrophied cardiomyopathy & 284 \\
\hline arrhythmogenic right ventricular dysplasia & 284 \\
\hline Takotsubo cardiomyopathy & 285 \\
\hline ischaemic heart disease & 283 \\
\hline recent myocardial infarction & 283 \\
\hline heart failure (NYHA III, VI) & 283 \\
\hline \multicolumn{2}{|l|}{ arrhythmias } \\
\hline $\begin{array}{l}\text { recently converted atrial fibrillation conduction } \\
\text { block, VPB, bradycardia, VT }\end{array}$ & 286,287 \\
\hline myocarditis & 288 \\
\hline cardiac channelopathies & 121 \\
\hline hypertension & 289 \\
\hline \multicolumn{2}{|l|}{ Endocrine diseases } \\
\hline hypothyroidism & 290 \\
\hline hyperparathyroidism & 291 \\
\hline phaeochromocytoma & 292 \\
\hline hyperaldosteronism & 293 \\
\hline \multicolumn{2}{|l|}{ CNS } \\
\hline intracranial haemorrhage & 294 \\
\hline encephalitis & 295 \\
\hline $\begin{array}{l}\text { Autonomous nervous system lability } \\
\text { increased sympathetic tone }\end{array}$ & 101 \\
\hline $\begin{array}{l}\text { Family history } \\
\text { family members with definite LQT1 } \\
\text { unexplained SCD in family members }<30 \text { years old }\end{array}$ & 296 \\
\hline \multicolumn{2}{|l|}{ Intoxications } \\
\hline alcohol & 297 \\
\hline organophosphate & 298 \\
\hline \multicolumn{2}{|l|}{ Electrolyte imbalance } \\
\hline hypokalaemia & 299 \\
\hline $\begin{array}{l}\text { hypomagnesaemia } \\
\text { hypocalcaemia }\end{array}$ & 269 \\
\hline $\begin{array}{l}\text { Pharmacodynamic interactions } \\
\text { concomitant medications }\end{array}$ & 303-305 \\
\hline \multicolumn{2}{|l|}{ Pharmacokinetic factors } \\
\hline \multicolumn{2}{|l|}{ liver diseases } \\
\hline cirrhosis & 300 \\
\hline hepatic failure & 301 \\
\hline & Continued \\
\hline
\end{tabular}

Table VI. Contd

\begin{tabular}{ll}
\hline Risk factors & References \\
\hline renal diseases & 302 \\
concomitant medications & $303-305$ \\
foods, drinks, liquid protein diet & $306-309$ \\
genetic polymorphism (i.e. CYP) & \\
Other & \\
diabetes mellitus & 284 \\
anorexia nervosa/starvation & 310 \\
bulimia & 311 \\
obesity & 312 \\
HIV infection & 313 \\
\hline
\end{tabular}

CYP = cytochrome P450; NYHA = New York Heart Association heart failure classification; $\mathbf{S C D}=$ sudden cardiac death; $\mathbf{V P B}=$ ventricular premature beat; $\mathbf{V T}=$ ventricular tachycardia.

patients, such as those with congenital LQTS channelopathies. ${ }^{[315]}$

Potential drug interactions via inhibition of CYP isoenzymes were responsible for $24 \%$ of cases in a recent study of patients with acquired LQTS. ${ }^{[271]}$ Metabolic interactions can greatly increase the risk of TdP with commonly used drugs. For example, an increasing number of deaths and life-threatening events have been reported in response to methadone coadministered with various drugs. Wilcock and Beattie ${ }^{[316]}$ concluded that a major contributing factor is a lack of knowledge among clinicians about the need to carefully initiate and monitor the use of methadone because of its wide interindividual variation in pharmacokinetics. Terfenadine, an antihistamine that was withdrawn from the market, is metabolized by CYP3A4 and normally causes slight (mean $\sim 6 \mathrm{~ms}$ ) QT prolongation in humans. However, a study using in vitro microsomal preparations from human livers showed that coadministration with the antifungal agent ketoconazole (which inhibits CYP3A4) would be expected to increase terfenadine blood concentrations by 13- to 59-fold. ${ }^{[317]}$ Such high concentrations of terfenadine can cause marked QT prolongation and susceptibility to TdP. ${ }^{[318]}$ Mutations in genes encoding metabolizing enzymes (i.e. CYP2D6, CYP3A4) can substantially increase the serum concentrations of proarrhythmic drugs. The blood levels of the torsadogenic antipsychotic 
drug thioridazine and its metabolites increase and QT interval lengthens in patients with abnormal drug metabolism. ${ }^{[319]}$ Considering the many genetic variants in repolarization channel gene sequences and metabolizing enzymes that can predispose to TdP, and the increasing number of potential QT-prolonging drugs, efficient personalized medicine approaches to the prevention of TdP remain a major challenge.

Given the difficulties in avoiding exposure of patients to potential QT-prolonging interventions, efficient detection is important. ECG recordings should be obtained in patients treated with drugs that can cause LQTS if there is any concern for potential LQTS, and particularly if they have risk factors for LQTS or suspicious clinical symptoms such as palpitations, lightheadedness or syncope. A QTc $>500 \mathrm{~ms}$ substantially increases TdP risk in patients with congenital LQTS. ${ }^{[320]}$ In one study of acquired LQTS, the majority of TdP cases occurred at QTc $>500 \mathrm{~ms}^{\left[{ }^{[321]}\right.}$ In the DIAMOND (Danish Investigations of Arrhythmia and Mortality on Dofetilide) study, female gender, the severity of heart failure and QTc duration identified patients at increased risk of early TdP upon dofetilide exposure. ${ }^{[283]}$ In a large congenital LQTS patient database, the mean QTc was $482 \mathrm{~ms}$ and individual values ranged from 365 to $800 \mathrm{~ms}^{\left[{ }^{[322]} \mathrm{A}\right.}$ recent survey showed that practising emergency room physicians rely heavily on Bazett-corrected QTc to assess LQTS risk, and that physician education and improved QT assessment guidelines are important for detection and prevention of acquired LQTS-related tachyarrhythmias. ${ }^{[265]}$ Males with QTc $\leq 330 \mathrm{~ms}$ and females with QTc $\leq 340 \mathrm{~ms}$ should be suspected of having congenital SQTS, even if they are asymptomatic. ${ }^{[323]}$ With increasing awareness of drug-induced SQTS, similar criteria may be appropriate, although there is presently limited knowledge about the acquired condition.

In addition to ion-channel dysfunction, abnormalities in $\mathrm{K}^{+}$-channel trafficking due to congenital mutations or drug effects can cause LQTs. ${ }^{[319,324,325]}$ It was recently demonstrated that some drugs can improve the trafficking of ion channel proteins. Paradoxically, cisapride could produce a 'double hit' effect on repolarization by improving the trafficking of gain-offunction-mutated $\mathrm{I}_{\mathrm{Na}}$ channel (SCN5A) subunits, leading to QTc lengthening, compounded by the drug's blocking effect on $\mathrm{I}_{\mathrm{Kr}}$. Better understanding of such complexities may help to better predict and prevent acquired LQTS in the future.

\section{Conclusions}

Despite detailed preclinical and clinical proarrhythmia core batteries of safety pharmacology, drug proarrhythmia risk assessment remains imperfect. Thus, even drugs judged to have relatively low proarrhythmia risk may need further surveillance after marketing. Post-approval clinical trials or surveillance programmes focusing on a small number of specified potential arrhythmic outcomes might allow for earlier identification of proarrhythmic properties, leading to altered labelling or, where necessary, the withdrawal of a drug. ${ }^{[324]}$ Despite the great progress that has already been made, further work is needed to validate various preclinical proarrhythmia models and develop new, more sensitive, specific and clinically relevant models and proarrhythmia biomarkers. Newer transgenic models (e.g. rabbit, zebrafish) may provide helpful complementary approaches. ${ }^{[325]}$ In the future, more reliable preclinical data, developments in pharmacogenomics and more advanced detection of genetic disorders may allow for personalized therapy taking into account individual patient risk factors for proarrhythmia. In the meantime, clinicians must be aware of proarrhythmic drugs, proarrhythmia labelling restrictions and proarrhythmia risk factors to provide pharmacological treatment with minimal proarrhythmic risk.

\section{Acknowledgements}

The authors thank France Theriault for secretarial support, the Canadian Institutes for Health Research (MOP 68929) and the European-North American Atrial Fibrillation Research Alliance (ENAFRA) network award from Fondation Leducq (07-CVD-03) for funding, and the Heart and Stroke Foundation of Canada for fellowship support to ASF. The authors have no conflicts of interest that are directly relevant to the content of this review. 


\section{References}

1. Lloyd-Jones D, Adams R, Carnethon M, et al. Heart disease and stroke statistics -2009 update: a report from the American Heart Association Statistics Committee and Stroke Statistics Subcommittee. Circulation 2009; 119 (3): 480-6

2. Zipes DP, Camm AJ, Borggrefe M, et al. ACC/AHA/ESC 2006 Guidelines for management of patients with ventricular arrhythmias and the prevention of sudden cardiac death: a report of the American College of Cardiology/American Heart Association Task Force and the European Society of Cardiology Committee for Practice Guidelines (writing committee to develop guidelines for management of patients with ventricular arrhythmias and the prevention of sudden cardiac death): developed in collaboration with the European Heart Rhythm Association and the Heart Rhythm Society. Circulation 2006; 114 (10): e385-484

3. The Cardiac Arrhythmia Suppression Trial (CAST) Investigators. Preliminary report: effect of encainide and flecainide on mortality in a randomized trial of arrhythmia suppression after myocardial infarction. N Engl J Med 1989; 321 (6): 406-12

4. Waldo AL, Camm AJ, deRuyter H, et al. Effect of d-sotalol on mortality in patients with left ventricular dysfunction after recent and remote myocardial infarction: the SWORD Investigators (Survival With ORal d-Sotalol). Lancet 1996; 348 (9019): 7-12

5. Frey W. Weitere erfahrungen mit chinidin bei absoluter herzun-regelmäßigkeit. Wien Med Wschr 1918; 55: 849-53

6. Selzer A, Wray HW. Quinidine syncope: paroxysmal ventricular fibrillation occurring during treatment of chronic atrial arrhythmias. Circulation 1964; 30: 17-26

7. Viskin S. Long QT syndromes and torsade de pointes. Lancet 1999; 354 (9190): 1625-33

8. Dessertenne F. Ventricular tachycardia with 2 variable opposing foci. Arch Mal Coeur Vaiss 1966; 59 (2): 263-72

9. Zeltser D, Justo D, Halkin A, et al. Drug-induced atrioventricular block: prognosis after discontinuation of the culprit drug. J Am Coll Cardiol 2004; 44 (1): 105-8

10. Farkas A, Qureshi A, Curtis MJ. Inadequate ischaemiaselectivity limits the antiarrhythmic efficacy of mibefradil during regional ischaemia and reperfusion in the rat isolated perfused heart. Br J Pharmacol 1999; 128 (1): 41-50

11. Watanabe $Y$. Effects of calcium and sodium concentrations on atrioventricular conduction: experimental study in rabbit hearts with clinical implications on heart block and slow calcium channel blocking agent usage. Am Heart J 1981; 102 (5): 883-91

12. Oros A, Beekman JD, Vos MA. The canine model with chronic, complete atrio-ventricular block. Pharmacol Ther 2008; 119 (2): 168-78

13. Fenichel RR, Malik M, Antzelevitch C, et al. Drug-induced torsades de pointes and implications for drug development. J Cardiovasc Electrophysiol 2004; 15 (4): 475-95

14. Haverkamp W, Breithardt G, Camm AJ, et al. The potential for QT prolongation and pro-arrhythmia by nonanti-arrhythmic drugs: clinical and regulatory implications: report on a Policy Conference of the European Society of Cardiology. Cardiovasc Res 2000; 47 (2): 219-33
15. Carlsson L. The anaesthetised methoxamine-sensitised rabbit model of torsades de pointes. Pharmacol Ther 2008; 119 (2): 160-7

16. Roden DM, Anderson ME. Proarrhythmia. Handb Exp Pharmacol 2006; (171): 73-97

17. Sarapa N, Britto MR. Challenges of characterizing proarrhythmic risk due to QTc prolongation induced by nonadjuvant anticancer agents. Expert Opin Drug Saf 2008; 7 (3): 305-18

18. Thomsen MB, Matz J, Volders PG, et al. Assessing the proarrhythmic potential of drugs: current status of models and surrogate parameters of torsades de pointes arrhythmias. Pharmacol Ther 2006; 112 (1): 150-70

19. International Conference on Harmonisation; guidance on S7B nonclinical evaluation of the potential for delayed ventricular repolarization (QT interval prolongation) by human pharmaceuticals; availability. Notice. Fed Regist 2005; 70 (202): 61133-4

20. International Conference on Harmonisation; guidance on E14 clinical evaluation of QT/QTc interval prolongation and proarrhythmic potential for non-antiarrhythmic drugs; availability. Notice. Fed Regist 2005; 70 (202): 61134-5

21. Jervell A, Lange-Nielsen F. Congenital deaf-mutism, functional heart disease with prolongation of the Q-T interval and sudden death. Am Heart J 1957; 54 (1): 59-68

22. Romano C, Gemme G, Pongiglione R. Rare cardiac arrhythmias of the pediatric age: I, repetitive paroxysmal tachycardia. Minerva Pediatr 1963; 15: 1155-64

23. Ward OC. A new familial cardiac syndrome in children. J Ir Med Assoc 1964; 54: 103-6

24. Roden DM. Cellular basis of drug-induced torsades de pointes. Br J Pharmacol 2008; 154 (7): 1502-7

25. Shah RR, Hondeghem LM. Refining detection of druginduced proarrhythmia: QT interval and TRIaD. Heart Rhythm 2005; 2 (7): 758-72

26. Jackman WM, Friday KJ, Anderson JL, et al. The long QT syndromes: a critical review, new clinical observations and a unifying hypothesis. Prog Cardiovasc Dis 1988; 31 (2): 115-72

27. Belardinelli L, Antzelevitch C, Vos MA. Assessing predictors of drug-induced torsade de pointes. Trends Pharmacol Sci 2003; 24 (12): 619-25

28. Sipido KR, Varro A, Eisner D. Sodium calcium exchange as a target for antiarrhythmic therapy. Handb Exp Pharmacol 2006; (171): 73-97

29. Gallacher DJ, Van de Water A, van der Linde H, et al. In vivo mechanisms precipitating torsades de pointes in a canine model of drug-induced long-QT1 syndrome. Cardiovasc Res 2007; 76 (2): 247-56

30. Ben Caref E, Boutjdir M, Himel HD, et al. Role of subendocardial Purkinje network in triggering torsade de pointes arrhythmia in experimental long QT syndrome. Europace 2008; 10 (10): 1218-23

31. Nattel S, Quantz MA. Pharmacological response of quinidine induced early afterdepolarisations in canine cardiac Purkinje fibres: insights into underlying ionic mechanisms. Cardiovasc Res 1988; 22 (11): 808-17

32. Tweedie D, O'Gara P, Harding SE, et al. The effect of alterations to action potential duration on beta-adrenoceptormediated aftercontractions in human and guinea-pig 
ventricular myocytes. J Mol Cell Cardiol 1997; 29 (5): 1457-67

33. Volders PG, Kulcsar A, Vos MA, et al. Similarities between early and delayed afterdepolarizations induced by isoproterenol in canine ventricular myocytes. Cardiovasc Res 1997; 34 (2): 348-59

34. Mazur A, Roden DM, Anderson ME. Systemic administration of calmodulin antagonist W-7 or protein kinase A inhibitor $\mathrm{H}-8$ prevents torsade de pointes in rabbits. Circulation 1999; 100 (24): 2437-42

35. Farkas AS, Makra P, Csik N, et al. The role of the $\mathrm{Na}+/ \mathrm{Ca} 2+$ exchanger, $\mathrm{I}(\mathrm{Na})$ and $\mathrm{I}(\mathrm{CaL})$ in the genesis of dofetilide-induced torsades de pointes in isolated, AV-blocked rabbit hearts. Br J Pharmacol 2009; 156 (6): 920-32

36. Hamlin RL, Kijtawornrat A. Use of the rabbit with a failing heart to test for torsadogenicity. Pharmacol Ther 2008; 119 (2): 179-85

37. Zygmunt AC, Goodrow RJ, Antzelevitch C. I(NaCa) contributes to electrical heterogeneity within the canine ventricle. Am J Physiol Heart Circ Physiol 2000; 278 (5): H1671-8

38. Milberg P, Pott C, Fink M, et al. Inhibition of the $\mathrm{Na}+/ \mathrm{Ca} 2+$ exchanger suppresses torsades de pointes in an intact heart model of long QT syndrome-2 and long QT syndrome-3. Heart Rhythm 2008; 5 (10): 1444-52

39. Antzelevitch C. Ionic, molecular, and cellular bases of QTinterval prolongation and torsade de pointes. Europace 2007; 9 Suppl. 4: iv4-15

40. Milberg P, Reinsch N, Wasmer K, et al. Transmural dispersion of repolarization as a key factor of arrhythmogenicity in a novel intact heart model of LQT3. Cardiovasc Res 2005; 65 (2): 397-404

41. Antzelevitch C. Drug-induced spatial dispersion of repolarization. Cardiol J 2008; 15 (2): 100-21

42. Chen YJ, Hsieh MH, Chiou CW, et al. Electropharmacologic characteristics of ventricular proarrhythmia induced by ibutilide. J Cardiovasc Pharmacol 1999; 34 (2): 237-47

43. Haapalahti P, Viitasalo M, Perhonen M, et al. Electrocardiographic interventricular dispersion of repolarization during autonomic adaptation in LQT1 subtype of long QT syndrome. Scand Cardiovasc J 2008; 42 (2): 130-6

44. Vos MA, Gorenek B, Verduyn SC, et al. Observations on the onset of torsade de pointes arrhythmias in the acquired long QT syndrome. Cardiovasc Res 2000; 48 (3): 421-9

45. Hondeghem LM, Carlsson L, Duker G. Instability and triangulation of the action potential predict serious proarrhythmia, but action potential duration prolongation is antiarrhythmic. Circulation 2001; 103 (15): 2004-13

46. Thomsen MB, Verduyn SC, Stengl M, et al. Increased short-term variability of repolarization predicts d-sotalolinduced torsades de pointes in dogs. Circulation 2004; 110 (16): 2453-9

47. Hondeghem LM. Relative contributions of TRIaD and QT to proarrhythmia. J Cardiovasc Electrophysiol 2007; 18 (6): 655-7

48. Sicouri S, Glass A, Ferreiro M, et al. Transseptal dispersion of repolarization and its role in the development of tor- sade de pointes arrhythmias. J Cardiovasc Electrophysiol. Epub 2009 Nov 10

49. Kay GN, Plumb VJ, Arciniegas JG, et al. Torsade de pointes: the long-short initiating sequence and other clinical features: observations in 32 patients. J Am Coll Cardiol 1983; 2 (5): 806-17

50. Noda T, Shimizu W, Satomi K, et al. Classification and mechanism of torsade de pointes initiation in patients with congenital long QT syndrome. Eur Heart J 2004; 25 (23): 2149-54

51. El-Sherif N, Caref EB, Chinushi M, et al. Mechanism of arrhythmogenicity of the short-long cardiac sequence that precedes ventricular tachyarrhythmias in the long QT syndrome. J Am Coll Cardiol 1999; 33 (5): 1415-23

52. Liu J, Laurita KR. The mechanism of pause-induced torsade de pointes in long QT syndrome. J Cardiovasc Electrophysiol 2005; 16 (9): 981-7

53. El-Sherif N, Turitto G. Torsade de pointes. Curr Opin Cardiol 2003; 18 (1): 6-13

54. El-Sherif N, Chinushi M, Caref EB, et al. Electrophysiological mechanism of the characteristic electrocardiographic morphology of torsade de pointes tachyarrhythmias in the long-QT syndrome: detailed analysis of ventricular tridimensional activation patterns. Circulation 1997; 96 (12): 4392-9

55. Johnson JN, Tester DJ, Perry J, et al. Prevalence of earlyonset atrial fibrillation in congenital long QT syndrome. Heart Rhythm 2008; 5 (5): 704-9

56. Seslar SP, Shepard SM, Berul CI. "Atrial torsades de pointes" in the long QT syndrome. J Interv Card Electrophysiol 2009; 24 (2): 95-7

57. Kirchhof P, Eckardt L, Franz MR, et al. Prolonged atrial action potential durations and polymorphic atrial tachyarrhythmias in patients with long QT syndrome. J Cardiovasc Electrophysiol 2003; 14 (10): 1027-33

58. Kirchhof P, Eckardt L, Monnig G, et al. A patient with "atrial torsades de pointes". J Cardiovasc Electrophysiol 2000; 11 (7): 806-11

59. Stansfeld PJ, Sutcliffe MJ, Mitcheson JS. Molecular mechanisms for drug interactions with hERG that cause long QT syndrome. Expert Opin Drug Metab Toxicol 2006; 2 (1): 81-94

60. Carlsson L. In vitro and in vivo models for testing arrhythmogenesis in drugs. J Intern Med 2006; 259 (1): 70-80

61. Gintant GA. Preclinical torsades-de-pointes screens: advantages and limitations of surrogate and direct approaches in evaluating proarrhythmic risk. Pharmacol Ther 2008; 119 (2): 199-209

62. Lawrence CL, Bridgland-Taylor MH, Pollard CE, et al. A rabbit Langendorff heart proarrhythmia model: predictive value for clinical identification of torsades de pointes. Br J Pharmacol 2006; 149 (7): 845-60

63. Lawrence CL, Pollard CE, Hammond TG, et al. In vitro models of proarrhythmia. Br J Pharmacol 2008; 154 (7): 1516-22

64. Lewis BH, Antman EM, Graboys TB. Detailed analysis of 24 hour ambulatory electrocardiographic recordings during ventricular fibrillation or torsade de pointes. J Am Coll Cardiol 1983; 2 (3): 426-36 
65. Yan GX, Wu Y, Liu T, et al. Phase 2 early afterdepolarization as a trigger of polymorphic ventricular tachycardia in acquired long-QT syndrome: direct evidence from intracellular recordings in the intact left ventricular wall. Circulation 2001; 103 (23): 2851-6

66. Hlaing T, DiMino T, Kowey PR, et al. ECG repolarization waves: their genesis and clinical implications. Ann Noninvasive Electrocardiol 2005; 10 (2): 211-23

67. Armoundas AA, Nanke T, Cohen RJ. Images in cardiovascular medicine: $\mathrm{T}$-wave alternans preceding torsade de pointes ventricular tachycardia. Circulation 2000; 101 (21): 2550

68. Tomcsanyi J, Somloi M, Fresz T, et al. T-wave alternans and torsade de pointes ventricular tachycardia in a patient with intracerebral hemorrhage. Orv Hetil 2003; 144 (42): 2077-9

69. Wegener FT, Ehrlich JR, Hohnloser SH. Amiodaroneassociated macroscopic T-wave alternans and torsade de pointes unmasking the inherited long QT syndrome. Europace 2008; 10 (1): 112-3

70. Cutler MJ, Rosenbaum DS. Risk stratification for sudden cardiac death: is there a clinical role for T wave alternans? Heart Rhythm 2009; 6 (8 Suppl.): S56-61

71. Garcia Ede V. T-wave alternans: reviewing the clinical performance, understanding limitations, characterizing methodologies. Ann Noninvasive Electrocardiol 2008; 13 (4): 401-20

72. Yan GX, Antzelevitch C. Cellular basis for the normal T wave and the electrocardiographic manifestations of the long-QT syndrome. Circulation 1998; 98 (18): 1928-36

73. Antzelevitch C, Oliva A. Amplification of spatial dispersion of repolarization underlies sudden cardiac death associated with catecholaminergic polymorphic VT, long QT, short QT and Brugada syndromes. J Intern Med 2006; 259 (1): 48-58

74. Wu L, Guo D, Li H, et al. Role of late sodium current in modulating the proarrhythmic and antiarrhythmic effects of quinidine. Heart Rhythm 2008; 5 (12): 1726-34

75. Yamaguchi M, Shimizu M, Ino $H$, et al. $\mathrm{T}$ wave peakto-end interval and QT dispersion in acquired long QT syndrome: a new index for arrhythmogenicity. Clin Sci (Lond) 2003; 105 (6): 671-6

76. Zhang H, Kharche S, Holden AV, et al. Repolarisation and vulnerability to re-entry in the human heart with short QT syndrome arising from KCNQ1 mutation: a simulation study. Prog Biophys Mol Biol 2008; 96 (1-3): 112-31

77. Letsas KP, Weber R, Astheimer K, et al. $\mathrm{T}_{\text {peak }}-\mathrm{T}_{\text {end }}$ interval and $\mathrm{T}_{\text {peak }}-\mathrm{T}_{\text {end }} / \mathrm{QT}$ ratio as markers of ventricular tachycardia inducibility in subjects with Brugada ECG phenotype. Europace 2010; 12 (2): 271-4

78. Nemec J, Hejlik JB, Shen WK, et al. Catecholamineinduced T-wave lability in congenital long QT syndrome: a novel phenomenon associated with syncope and cardiac arrest. Mayo Clin Proc 2003; 78 (1): 40-50

79. Carlsson L, Andersson B, Linhardt G, et al. Assessment of the ion channel-blocking profile of the novel combined ion channel blocker AZD1305 and its proarrhythmic potential versus dofetilide in the methoxamine-sensitized rabbit in vivo. J Cardiovasc Pharmacol 2009; 54 (1): 82-9
80. Lengyel C, Varro A, Tabori K, et al. Combined pharmacological block of $\mathrm{I}(\mathrm{Kr})$ and $\mathrm{I}(\mathrm{Ks})$ increases short-term QT interval variability and provokes torsades de pointes. Br J Pharmacol 2007; 151 (7): 941-51

81. Hinterseer M, Thomsen MB, Beckmann BM, et al. Beat-tobeat variability of QT intervals is increased in patients with drug-induced long-QT syndrome: a case control pilot study. Eur Heart J 2008; 29 (2): 185-90

82. Hinterseer M, Beckmann BM, Thomsen MB, et al. Relation of increased short-term variability of QT interval to congenital long-QT syndrome. Am J Cardiol 2009; 103 (9): 1244-8

83. van der Linde H, Van de Water A, Loots W, et al. A new method to calculate the beat-to-beat instability of QT duration in drug-induced long QT in anesthetized dogs. J Pharmacol Toxicol Methods 2005; 52 (1): 168-77

84. Brennan M, Palaniswami M, Kamen P. Do existing measures of Poincare plot geometry reflect nonlinear features of heart rate variability? IEEE Trans Biomed Eng 2001; 48 (11): 1342-7

85. Perkiomaki JS, Zareba W, Nomura A, et al. Repolarization dynamics in patients with long QT syndrome. J Cardiovasc Electrophysiol 2002; 13 (7): 651-6

86. Vincze D, Farkas AS, Rudas L, et al. Relevance of anaesthesia for dofetilide-induced torsades de pointes in alpha ${ }_{1}$ adrenoceptor-stimulated rabbits. Br J Pharmacol 2008; 153 (1): 75-89

87. Copie X, Le Heuzey JY, Iliou MC, et al. Correlation between time-domain measures of heart rate variability and scatterplots in postinfarction patients. Pacing Clin Electrophysiol 1996; 19 (3): 342-7

88. Schoenwald RD, Isaacs VE. QT corrected for heart rate: a new approach and its application. Arch Int Pharmacodyn Ther 1974; 211 (1): 34-48

89. Berger RD, Kasper EK, Baughman KL, et al. Beat-to-beat QT interval variability: novel evidence for repolarization lability in ischemic and nonischemic dilated cardiomyopathy. Circulation 1997; 96 (5): 1557-65

90. Bilchick K, Viitasalo M, Oikarinen L, et al. Temporal repolarization lability differences among genotyped patients with the long QT syndrome. Am J Cardiol 2004; 94 (10): 1312-6

91. Champeroux P, Martel E, Fowler JS, et al. Calculation of QT shift in non clinical safety pharmacology studies. J Pharmacol Toxicol Methods 2009; 59 (2): 73-85

92. Fossa AA. Assessing QT prolongation in conscious dogs: validation of a beat-to-beat method. Pharmacol Ther 2008; 119 (2): 133-40

93. Krahn AD, Yee R, Chauhan V, et al. Beta blockers normalize QT hysteresis in long QT syndrome. Am Heart J 2002; 143 (3): 528-34

94. Van Deuren B, Van Ammel K, Somers Y, et al. The fentanyl/etomidate-anaesthetised beagle (FEAB) dog: a versatile in vivo model in cardiovascular safety research. J Pharmacol Toxicol Methods 2009; 60 (1): 11-23

95. Bertinieri G, Di Rienzo M, Cavallazzi A, et al. Evaluation of baroreceptor reflex by blood pressure monitoring in unanesthetized cats. Am J Physiol 1988; 254 (2 Pt 2): H377-83 
96. Schwartz PJ, Vanoli E, Crotti L, et al. Neural control of heart rate is an arrhythmia risk modifier in long QT syndrome. J Am Coll Cardiol 2008; 51 (9): 920-9

97. Billman GE, Schwartz PJ, Stone HL. Baroreceptor reflex control of heart rate: a predictor of sudden cardiac death. Circulation 1982; 66 (4): 874-80

98. Nattel S, Comtois P. Teasing out circadian variability in heart rate turbulence: a new approach to detecting biorhythms underlying cardiac function. Heart Rhythm 2007; 4 (3): 301-3

99. Guzik P, Schmidt G. A phenomenon of heart-rate turbulence, its evaluation, and prognostic value. Card Electrophysiol Rev 2002; 6 (3): 256-61

100. Grimm W, Schmidt G, Maisch B, et al. Prognostic significance of heart rate turbulence following ventricular premature beats in patients with idiopathic dilated cardiomyopathy. J Cardiovasc Electrophysiol 2003; 14 (8): 819-24

101. Verrier RL, Antzelevitch C. Autonomic aspects of arrhythmogenesis: the enduring and the new. Curr Opin Cardiol 2004; 19 (1): 2-11

102. Lombardi F. Clinical implications of present physiological understanding of HRV components. Card Electrophysiol Rev 2002; 6 (3): 245-9

103. Pierre B, Babuty D, Poret P, et al. Abnormal nocturnal heart rate variability and QT dynamics in patients with Brugada syndrome. Pacing Clin Electrophysiol 2007; 30 Suppl. 1: S188-91

104. Perkiomaki JS, Zareba W, Couderc JP, et al. Heart rate variability in patients with congenital long QT syndrome. Ann Noninvasive Electrocardiol 2001; 6 (4): 298-304

105. Shimizu W, Antzelevitch C. Differential effects of betaadrenergic agonists and antagonists in LQT1, LQT2 and LQT3 models of the long QT syndrome. J Am Coll Cardiol 2000; 35 (3): 778-86

106. Michael G, Kane KA, Coker SJ. Adrenaline reveals the torsadogenic effect of combined blockade of potassium channels in anaesthetized guinea pigs. Br J Pharmacol 2008; 154 (7): 1414-26

107. Ring CL, Idriss SF, Neu WK. Variability of action potential duration in pharmacologically induced long QT syndrome type 1. Conf Proc IEEE Eng Med Biol Soc 2009; 1: 4520-2

108. Seebohm G, Pusch M, Chen J, et al. Pharmacological activation of normal and arrhythmia-associated mutant KCNQ1 potassium channels. Circ Res 2003; 93 (10): 941-7

109. Nissen JD, Diness JG, Diness TG, et al. Pharmacologically induced long QT type 2 can be rescued by activation of IKs with benzodiazepine R-L3 in isolated guinea pig cardiomyocytes. J Cardiovasc Pharmacol 2009; 54 (2): 169-77

110. Farkas AS, Acsai K, Toth A, et al. Importance of extracardiac alpha $_{1}$-adrenoceptor stimulation in assisting dofetilide to induce torsade de pointes in rabbit hearts. Eur J Pharmacol 2006; 537 (1-3): 118-25

111. Farkas A, Dempster J, Coker SJ. Importance of vagally mediated bradycardia for the induction of torsade de pointes in an in vivo model. Br J Pharmacol 2008; 154 (5): 958-70
112. Yamauchi S, Yamaki M, Watanabe T, et al. Restitution properties and occurrence of ventricular arrhythmia in LQT2 type of long QT syndrome. J Cardiovasc Electrophysiol 2002; 13 (9): 910-4

113. Hansen RS, Diness TG, Christ T, et al. Activation of human ether-a-go-go-related gene potassium channels by the diphenylurea 1,3-bis-(2-hydroxy-5-trifluoromethyl-phenyl)urea (NS1643). Mol Pharmacol 2006; 69 (1): 266-77

114. Hansen RS, Diness TG, Christ T, et al. Biophysical characterization of the new human ether-a-go-go-related gene channel opener NS3623 [N-(4-bromo-2-(1H-tetrazol-5-yl)phenyl)-N'-(3'-trifluoromethylphenyl)urea]. Mol Pharmacol 2006; 70 (4): 1319-29

115. Grunnet M, Hansen RS, Olesen SP. hERG1 channel activators: a new anti-arrhythmic principle. Prog Biophys Mol Biol 2008; 98 (2-3): 347-62

116. Yap YG, Behr ER, Camm AJ. Drug-induced Brugada syndrome. Europace 2009; 11 (8): 989-94

117. Veltmann C, Wolpert C, Sacher F, et al. Response to intravenous ajmaline: a retrospective analysis of 677 ajmaline challenges. Europace 2009; 11 (10): 1345-52

118. Stokoe KS, Balasubramaniam R, Goddard CA, et al. Effects of flecainide and quinidine on arrhythmogenic properties of Scn $5 \mathrm{a}+/$ - murine hearts modelling the Brugada syndrome. J Physiol 2007; 581 (Pt 1): 255-75

119. Michael G, Dempster J, Kane KA, et al. Potentiation of E-4031-induced torsade de pointes by HMR 1556 or ATXII is not predicted by action potential short-term variability or triangulation. Br J Pharmacol 2007; 152 (8): 1215-27

120. Milberg P, Reinsch N, Osada N, et al. Verapamil prevents torsade de pointes by reduction of transmural dispersion of repolarization and suppression of early afterdepolarizations in an intact heart model of LQT3. Basic Res Cardiol 2005; 100 (4): 365-71

121. Patel C, Antzelevitch C. Pharmacological approach to the treatment of long and short QT syndromes. Pharmacol Ther 2008; 118 (1): 138-51

122. Antzelevitch C, Pollevick GD, Cordeiro JM, et al. Loss-offunction mutations in the cardiac calcium channel underlie a new clinical entity characterized by ST-segment elevation, short QT intervals, and sudden cardiac death. Circulation 2007; 115 (4): 442-9

123. Sicouri S, Timothy KW, Zygmunt AC, et al. Cellular basis for the electrocardiographic and arrhythmic manifestations of Timothy syndrome: effects of ranolazine. Heart Rhythm 2007; 4 (5): 638-47

124. Cheng HC, Incardona J. Models of torsades de pointes: effects of FPL64176, DPI201106, dofetilide, and chromanol 293B in isolated rabbit and guinea pig hearts. J Pharmacol Toxicol Methods 2009; 60 (2): 174-84

125. Chaudhry GM, Haffajee CI. Antiarrhythmic agents and proarrhythmia. Crit Care Med 2000; 28 (10 Suppl.): N158-64

126. Remme CA, Verkerk AO, Nuyens D, et al. Overlap syndrome of cardiac sodium channel disease in mice carrying the equivalent mutation of human SCN5A-1795insD. Circulation 2006; 114 (24): 2584-94 
127. Remme CA, Wilde AA, Bezzina CR. Cardiac sodium channel overlap syndromes: different faces of SCN5A mutations. Trends Cardiovasc Med 2008; 18 (3): 78-87

128. Postema PG, Van den Berg M, Van Tintelen JP, et al. Founder mutations in the Netherlands: SCN5a 1795insD, the first described arrhythmia overlap syndrome and one of the largest and best characterised families worldwide. Neth Heart J 2009; 17 (11): 422-8

129. Algra A, Tijssen JG, Roelandt JR, et al. QT interval variables from 24 hour electrocardiography and the two year risk of sudden death. Br Heart J 1993; 70 (1): 43-8

130. Gussak I, Brugada P, Brugada J, et al. Idiopathic short QT interval: a new clinical syndrome? Cardiology 2000; 94 (2): 99-102

131. Bellocq C, van Ginneken AC, Bezzina CR, et al. Mutation in the KCNQ1 gene leading to the short QT-interval syndrome. Circulation 2004; 109 (20): 2394-7

132. Brugada R, Hong K, Dumaine R, et al. Sudden death associated with short-QT syndrome linked to mutations in HERG. Circulation 2004; 109 (1): 30-5

133. Priori SG, Pandit SV, Rivolta I, et al. A novel form of short QT syndrome (SQT3) is caused by a mutation in the KCNJ2 gene. Circ Res 2005; 96 (7): 800-7

134. Shah RR. Drug-induced QT interval shortening: potential harbinger of proarrhythmia and regulatory perspectives. Br J Pharmacol 2010; 159 (1): 58-69

135. Kang J, Chen XL, Wang $\mathrm{H}$, et al. Discovery of a small molecule activator of the human ether-a-go-go-related gene (HERG) cardiac K+ channel. Mol Pharmacol 2005; 67 (3): 827-36

136. Zhou J, Augelli-Szafran CE, Bradley JA, et al. Novel potent human ether-a-go-go-related gene (hERG) potassium channel enhancers and their in vitro antiarrhythmic activity. Mol Pharmacol 2005; 68 (3): 876-84

137. Pugsley MK, Hancox JC, Curtis MJ. Perception of validity of clinical and preclinical methods for assessment of torsades de pointes liability. Pharmacol Ther 2008; 119 (2): 115-7

138. Abi-Gerges N, Small BG, Lawrence CL, et al. Evidence for gender differences in electrophysiological properties of canine Purkinje fibres. Br J Pharmacol 2004; 142 (8): 1255-64

139. Wang D, Patel C, Cui C, et al. Preclinical assessment of drug-induced proarrhythmias: role of the arterially perfused rabbit left ventricular wedge preparation. Pharmacol Ther 2008; 119 (2): 141-51

140. Tomaselli GF, Rose J. Molecular aspects of arrhythmias associated with cardiomyopathies. Curr Opin Cardiol 2000; 15 (3): 202-8

141. Vos MA, van Opstal JM, Leunissen JD, et al. Electrophysiologic parameters and predisposing factors in the generation of drug-induced torsade de pointes arrhythmias. Pharmacol Ther 2001; 92 (2-3): 109-22

142. Dhein S, Perlitz F, Mohr FW. An in vitro model for assessment of drug-induced torsade de pointes arrhythmia: effects of haloperidol and dofetilide on potential duration, repolarization inhomogeneities, and torsade de pointes arrhythmia. Naunyn Schmiedebergs Arch Pharmacol 2008; 378 (6): 631-44
143. Carlsson L, Almgren O, Duker G. QTU-prolongation and torsades de pointes induced by putative class III antiarrhythmic agents in the rabbit: etiology and interventions. J Cardiovasc Pharmacol 1990; 16 (2): 276-85

144. Vos MA, Verduyn SC, Gorgels AP, et al. Reproducible induction of early afterdepolarizations and torsade de pointes arrhythmias by d-sotalol and pacing in dogs with chronic atrioventricular block. Circulation 1995; 91 (3): 864-72

145. Toyoshima S, Kanno A, Kitayama T, et al. QT PRODACT: in vivo QT assay in the conscious dog for assessing the potential for QT interval prolongation by human pharmaceuticals. J Pharmacol Sci 2005; 99 (5): 459-71

146. Ando K, Hombo T, Kanno A, et al. QT PRODACT: in vivo $\mathrm{QT}$ assay with a conscious monkey for assessment of the potential for drug-induced QT interval prolongation. J Pharmacol Sci 2005; 99 (5): 487-500

147. Lindgren S, Bass AS, Briscoe R, et al. Benchmarking safety pharmacology regulatory packages and best practice. J Pharmacol Toxicol Methods 2008; 58 (2): 99-109

148. Bass AS, Darpo B, Breidenbach A, et al. International Life Sciences Institute (Health and Environmental Sciences Institute, HESI) initiative on moving towards better predictors of drug-induced torsades de pointes. $\mathrm{Br} \mathrm{J}$ Pharmacol 2008; 154 (7): 1491-501

149. Aronov AM. Predictive in silico modeling for hERG channel blockers. Drug Discov Today 2005; 10 (2): 149-55

150. Kleber AG, Rudy Y. Basic mechanisms of cardiac impulse propagation and associated arrhythmias. Physiol Rev 2004; 84 (2): 431-88

151. Arrigoni C, Crivori P. Assessment of QT liabilities in drug development. Cell Biol Toxicol 2007; 23 (1): 1-13

152. Bender A, Scheiber J, Glick M, et al. Analysis of pharmacology data and the prediction of adverse drug reactions and off-target effects from chemical structure. Chem Med Chem 2007; 2 (6): 861-73

153. Grandi E, Pasqualini FS, Pes C, et al. Theoretical investigation of action potential duration dependence on extracellular $\mathrm{Ca} 2+$ in human cardiomyocytes. J Mol Cell Cardiol 2009; 46 (3): 332-42

154. Vecchietti S, Grandi E, Severi S, et al. In silico assessment of Y1795C and Y1795H SCN5A mutations: implication for inherited arrhythmogenic syndromes. Am J Physiol Heart Circ Physiol 2007; 292 (1): H56-65

155. Roden DM. Taking the "idio" out of "idiosyncratic": predicting torsades de pointes. Pacing Clin Electrophysiol 1998; 21 (5): 1029-34

156. Hancox JC, McPate MJ, El Harchi A, et al. The hERG potassium channel and hERG screening for drug-induced torsades de pointes. Pharmacol Ther 2008; 119 (2): 118-32

157. Nattel S, Duker G, Carlsson L. Model systems for the discovery and development of antiarrhythmic drugs. Prog Biophys Mol Biol 2008; 98 (2-3): 328-39

158. Kirsch GE, Trepakova ES, Brimecombe JC, et al. Variability in the measurement of hERG potassium channel inhibition: effects of temperature and stimulus pattern. J Pharmacol Toxicol Methods 2004; 50 (2): 93-101

159. Yao JA, Du X, Lu D, et al. Estimation of potency of HERG channel blockers: impact of voltage protocol and 
temperature. J Pharmacol Toxicol Methods 2005; 52 (1): 146-53

160. Sanguinetti MC, Jiang C, Curran ME, et al. A mechanistic link between an inherited and an acquired cardiac arrhythmia: HERG encodes the IKr potassium channel. Cell 1995; 81 (2): 299-307

161. Yang T, Snyders DJ, Roden DM. Rapid inactivation determines the rectification and $[\mathrm{K}+] \mathrm{o}$ dependence of the rapid component of the delayed rectifier $\mathrm{K}+$ current in cardiac cells. Circ Res 1997; 80 (6): 782-9

162. Stork D, Timin EN, Berjukow S, et al. State dependent dissociation of HERG channel inhibitors. Br J Pharmacol 2007; 151 (8): 1368-76

163. Yang T, Snyders D, Roden DM. Drug block of $\mathrm{I}(\mathrm{kr})$ : model systems and relevance to human arrhythmias. J Cardiovasc Pharmacol 2001; 38 (5): 737-44

164. Antzelevitch C, Belardinelli L, Zygmunt AC, et al. Electrophysiological effects of ranolazine, a novel antianginal agent with antiarrhythmic properties. Circulation 2004; 110 (8): 904-10

165. Schram G, Zhang L, Derakhchan K, et al. Ranolazine: ionchannel-blocking actions and in vivo electrophysiological effects. Br J Pharmacol 2004; 142 (8): 1300-8

166. Cavero I, Mestre M, Guillon JM, et al. Drugs that prolong QT interval as an unwanted effect: assessing their likelihood of inducing hazardous cardiac dysrhythmias. Expert Opin Pharmacother 2000; 1 (5): 947-73

167. Redfern WS, Carlsson L, Davis AS, et al. Relationships between preclinical cardiac electrophysiology, clinical QT interval prolongation and torsade de pointes for a broad range of drugs: evidence for a provisional safety margin in drug development. Cardiovasc Res 2003; 58 (1): 32-45

168. Ficker E, Dennis AT, Wang L, et al. Role of the cytosolic chaperones Hsp70 and Hsp90 in maturation of the cardiac potassium channel HERG. Circ Res 2003; 92 (12): e87-100

169. Unnikrishnan D, Dutcher JP, Varshneya N, et al. Torsades de pointes in 3 patients with leukemia treated with arsenic trioxide. Blood 2001; 97 (5): 1514-6

170. Wang L, Wible BA, Wan X, et al. Cardiac glycosides as novel inhibitors of human ether-a-go-go-related gene channel trafficking. J Pharmacol Exp Ther 2007; 320 (2): 525-34

171. Wible BA, Hawryluk P, Ficker E, et al. HERG-Lite: a novel comprehensive high-throughput screen for druginduced hERG risk. J Pharmacol Toxicol Methods 2005; 52 (1): 136-45

172. Rezazadeh S, Hesketh JC, Fedida D. Rb+ flux through hERG channels affects the potency of channel blocking drugs: correlation with data obtained using a highthroughput Rb+efflux assay. J Biomol Screen 2004; 9 (7): 588-97

173. Chaudhary KW, O'Neal JM, Mo ZL, et al. Evaluation of the rubidium efflux assay for preclinical identification of HERG blockade. Assay Drug Dev Technol 2006; 4 (1): 73-82

174. Titus SA, Beacham D, Shahane SA, et al. A new homogeneous high-throughput screening assay for profiling compound activity on the human ether-a-go-go-related gene channel. Anal Biochem 2009; 394 (1): 30-8
175. Meyer T, Sartipy P, Blind F, et al. New cell models and assays in cardiac safety profiling. Expert Opin Drug Metab Toxicol 2007; 3 (4): 507-17

176. Lu HR, Vlaminckx E, Hermans AN, et al. Predicting drug-induced changes in QT interval and arrhythmias: QT-shortening drugs point to gaps in the ICHS7B guidelines. Br J Pharmacol 2008; 154 (7): 1427-38

177. Hosaka Y, Iwata M, Kamiya N, et al. Mutational analysis of block and facilitation of HERG current by a class III anti-arrhythmic agent, nifekalant. Channels (Austin) 2007; 1 (3): 198-208

178. Jo SH, Hong HK, Chong SH, et al. Clomipramine block of the hERG K+ channel: accessibility to F656 and Y652. Eur J Pharmacol 2008; 592 (1-3): 19-25

179. Kamiya K, Niwa R, Morishima M, et al. Molecular determinants of hERG channel block by terfenadine and cisapride. J Pharmacol Sci 2008; 108 (3): 301-7

180. Shah RR. Drug-induced QT interval prolongation: regulatory guidance and perspectives on hERG channel studies. Novartis Found Symp 2005; 266: 251-80; discussion $80-5$

181. Witchel HJ. The hERG potassium channel as a therapeutic target. Expert Opin Ther Targets 2007; 11 (3): 321-36

182. Martin RL, McDermott JS, Salmen HJ, et al. The utility of hERG and repolarization assays in evaluating delayed cardiac repolarization: influence of multi-channel block. J Cardiovasc Pharmacol 2004; 43 (3): 369-79

183. Limberis JT, McDermott JS, Salmen HJ, et al. The effects of plasma proteins on delayed repolarization in vitro with cisapride, risperidone, and D,L-sotalol. J Pharmacol Toxicol Methods 2007; 56 (1): 11-7

184. Hanson LA, Bass AS, Gintant G, et al. ILSI-HESI cardiovascular safety subcommittee initiative: evaluation of three non-clinical models of QT prolongation. J Pharmacol Toxicol Methods 2006; 54 (2): 116-29

185. Lu HR, Vlaminckx E, Van de Water A, et al. In-vitro experimental models for the risk assessment of antibioticinduced QT prolongation. Eur J Pharmacol 2006; 553 (1-3): 229-39

186. Hayashi S, Kii Y, Tabo M, et al. QT PRODACT: a multisite study of in vitro action potential assays on $21 \mathrm{com}$ pounds in isolated guinea-pig papillary muscles. J Pharmacol Sci 2005; 99 (5): 423-37

187. Kii Y, Hayashi S, Tabo M, et al. QT PRODACT: evaluation of the potential of compounds to cause QT interval prolongation by action potential assays using guinea-pig papillary muscles. J Pharmacol Sci 2005; 99 (5): 449-57

188. Yan GX, Shimizu W, Antzelevitch C. Characteristics and distribution of $M$ cells in arterially perfused canine left ventricular wedge preparations. Circulation 1998; 98 (18): 1921-7

189. Poelzing S. Are electrophysiologically distinct M-cells a characteristic of the wedge preparation? Heart Rhythm 2009; 6 (7): 1035-7

190. Voss F, Opthof T, Marker J, et al. There is no transmural heterogeneity in an index of action potential duration in the canine left ventricle. Heart Rhythm 2009; 6 (7): 1028-34

191. Opthof T, Coronel R, Wilms-Schopman FJ, et al. Dispersion of repolarization in canine ventricle and the electro- 
cardiographic $\mathrm{T}$ wave: Tp-e interval does not reflect transmural dispersion. Heart Rhythm 2007; 4 (3): 341-8

192. Di Diego JM, Belardinelli L, Antzelevitch C. Cisaprideinduced transmural dispersion of repolarization and torsade de pointes in the canine left ventricular wedge preparation during epicardial stimulation. Circulation 2003; 108 (8): 1027-33

193. Wu L, Rajamani S, Li H, et al. Reduction of repolarization reserve unmasks the proarrhythmic role of endogenous late $\mathrm{Na}(+)$ current in the heart. Am J Physiol Heart Circ Physiol 2009; 297 (3): H1048-57

194. Extramiana F, Antzelevitch C. Amplified transmural dispersion of repolarization as the basis for arrhythmogenesis in a canine ventricular-wedge model of short-QT syndrome. Circulation 2004; 110 (24): 3661-6

195. Patel C, Antzelevitch C. Cellular basis for arrhythmogenesis in an experimental model of the SQT1 form of the short QT syndrome. Heart Rhythm 2008; 5 (4): 585-90

196. Calloe K, Cordeiro JM, Di Diego JM, et al. A transient outward potassium current activator recapitulates the electrocardiographic manifestations of Brugada syndrome. Cardiovasc Res 2009; 81 (4): 686-94

197. Morita H, Zipes DP, Fukushima-Kusano K, et al. Repolarization heterogeneity in the right ventricular outflow tract: correlation with ventricular arrhythmias in Brugada patients and in an in vitro canine Brugada model. Heart Rhythm 2008; 5 (5): 725-33

198. Joshi A, Dimino T, Vohra Y, et al. Preclinical strategies to assess QT liability and torsadogenic potential of new drugs: the role of experimental models. J Electrocardiol 2004; 37 Suppl.: 7-14

199. Liu T, Brown BS, Wu Y, et al. Blinded validation of the isolated arterially perfused rabbit ventricular wedge in preclinical assessment of drug-induced proarrhythmias. Heart Rhythm 2006; 3 (8): 948-56

200. Chen X, Cordes JS, Bradley JA, et al. Use of arterially perfused rabbit ventricular wedge in predicting arrhythmogenic potentials of drugs. J Pharmacol Toxicol Methods 2006; 54 (3): 261-72

201. Valentin JP, Hoffmann P, De Clerck F, et al. Review of the predictive value of the Langendorff heart model (Screenit system) in assessing the proarrhythmic potential of drugs. J Pharmacol Toxicol Methods 2004; 49 (3): 171-81

202. Hondeghem LM, Lu HR, van Rossem K, et al. Detection of proarrhythmia in the female rabbit heart: blinded validation. J Cardiovasc Electrophysiol 2003; 14 (3): 287-94

203. Guo L, Dong Z, Guthrie H. Validation of a guinea pig Langendorff heart model for assessing potential cardiovascular liability of drug candidates. J Pharmacol Toxicol Methods 2009; 60 (2): 833-43

204. Hondeghem LM, Hoffmann P. Blinded test in isolated female rabbit heart reliably identifies action potential duration prolongation and proarrhythmic drugs: importance of triangulation, reverse use dependence, and instability. J Cardiovasc Pharmacol 2003; 41 (1): 14-24

205. Dumotier BM, Deurinck M, Yang Y, et al. Relevance of in vitro SCREENIT results for drug-induced QT interval prolongation in vivo: a database review and analysis. Pharmacol Ther 2008; 119 (2): 152-9
206. Hondeghem LM. Use and abuse of QT and TRIaD in cardiac safety research: importance of study design and conduct. Eur J Pharmacol 2008; 584 (1): 1-9

207. Zabel M, Hohnloser SH, Behrens S, et al. Electrophysiologic features of torsades de pointes: insights from a new isolated rabbit heart model. J Cardiovasc Electrophysiol 1997; 8 (10): 1148-58

208. Johna R, Mertens H, Haverkamp W, et al. Clofilium in the isolated perfused rabbit heart: a new model to study proarrhythmia induced by class III antiarrhythmic drugs. Basic Res Cardiol 1998; 93 (2): 127-35

209. Milberg P, Hilker E, Ramtin S, et al. Proarrhythmia as a class effect of quinolones: increased dispersion of repolarization and triangulation of action potential predict torsades de pointes. J Cardiovasc Electrophysiol 2007; 18 (6): 647-54

210. Lu HR, Vlaminckx E, Van de Water A, et al. In-vitro experimental models for the risk assessment of antibiotic-induced QT prolongation. Eur J Pharmacol 2007; 577 (1-3): 222-32

211. Gray RA, Jalife J, Panfilov A, et al. Nonstationary vortexlike reentrant activity as a mechanism of polymorphic ventricular tachycardia in the isolated rabbit heart. Circulation 1995; 91 (9): 2454-69

212. Shimizu W, Antzelevitch C. Effects of a $\mathrm{K}(+)$ channel opener to reduce transmural dispersion of repolarization and prevent torsade de pointes in LQT1, LQT2, and LQT3 models of the long-QT syndrome. Circulation 2000; 102 (6): 706-12

213. Farkas A, Lepran I, Papp JG. Comparison of the antiarrhythmic and the proarrhythmic effect of almokalant in anaesthetised rabbits. Eur J Pharmacol 1998; 346 (2-3): 245-53

214. Farkas A, Coker SJ. Limited induction of torsade de pointes by terikalant and erythromycin in an in vivo model. Eur J Pharmacol 2002; 449 (1-2): 143-53

215. Farkas A, Coker SJ. Prevention of clofilium-induced torsade de pointes by prostaglandin E2 does not involve ATP-dependent K+ channels. Eur J Pharmacol 2003; 472 (3): 189-96

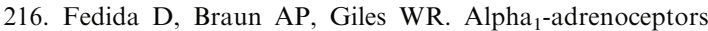
reduce background $\mathrm{K}+$ current in rabbit ventricular myocytes. J Physiol 1991; 441: 673-84

217. Fedida D, Braun AP, Giles WR. Alpha ${ }_{1}$-adrenoceptors in myocardium: functional aspects and transmembrane signaling mechanisms. Physiol Rev 1993; 73 (2): 469-87

218. Fedida D, Shimoni Y, Giles WR. Alpha-adrenergic modulation of the transient outward current in rabbit atrial myocytes. J Physiol 1990; 423: 257-77

219. Terzic A, Puceat M, Vassort G, et al. Cardiac alpha ${ }_{1}$-adrenoceptors: an overview. Pharmacol Rev 1993; 45 (2): 147-75

220. Steinberg SF, Kaplan LM, Inouye T, et al. Alpha-1 adrenergic stimulation of 1,4,5-inositol trisphosphate formation in ventricular myocytes. J Pharmacol Exp Ther 1989; 250 (3): 1141-8

221. Carlsson L, Drews L, Duker G. Rhythm anomalies related to delayed repolarization in vivo: influence of sarcolemmal $\mathrm{Ca}++$ entry and intracellular Ca++ overload. J Pharmacol Exp Ther 1996; 279 (1): 231-9

222. Wang WQ, Robertson C, Dhalla AK, et al. Antitorsadogenic effects of $(\{+/-\})-\mathrm{N}-(2,6$-dimethyl-phenyl)- 
(4[2-hydroxy-3-(2-methoxyphenoxy)propyl]-1-piperazine) (ranolazine) in anesthetized rabbits. J Pharmacol Exp Ther 2008; 325 (3): 875-81

223. Farkas A, Batey AJ, Coker SJ. How to measure electrocardiographic QT interval in the anaesthetized rabbit. J Pharmacol Toxicol Methods 2004; 50 (3): 175-85

224. Farkas A, Lepran I, Papp JG. Proarrhythmic effects of intravenous quinidine, amiodarone, D-sotalol, and almokalant in the anesthetized rabbit model of torsade de pointes. J Cardiovasc Pharmacol 2002; 39 (2): 287-97

225. Lu HR, Remeysen P, De Clerck F. Nonselective I(Kr)blockers do not induce torsades de pointes in the anesthetized rabbit during alpha ${ }_{1}$-adrenoceptor stimulation. J Cardiovasc Pharmacol 2000; 36 (6): 728-36

226. Provan G, Stanton A, Sutton A, et al. Development of a surgical approach for telemetering guinea pigs as a model for screening QT interval effects. J Pharmacol Toxicol Methods 2005; 52 (2): 223-8

227. Chaves AA, Keller WJ, O'Sullivan S, et al. Cardiovascular monkey telemetry: sensitivity to detect QT interval prolongation. J Pharmacol Toxicol Methods 2006; 54 (2): 150-8

228. Chaves AA, Zingaro GJ, Yordy MA, et al. A highly sensitive canine telemetry model for detection of QT interval prolongation: studies with moxifloxacin, haloperidol and MK499. J Pharmacol Toxicol Methods 2007; 56 (2): 103-14

229. van der Linde HJ, Van Deuren B, Teisman A, et al. The effect of changes in core body temperature on the QT interval in beagle dogs: a previously ignored phenomenon, with a method for correction. Br J Pharmacol 2008; 154 (7): $1474-81$

230. Han W, Chartier D, Li D, et al. Ionic remodeling of cardiac Purkinje cells by congestive heart failure. Circulation 2001; 104 (17): 2095-100

231. Nabauer M, Kaab S. Potassium channel down-regulation in heart failure. Cardiovasc Res 1998; 37 (2): 324-34

232. Tsuji Y, Zicha S, Qi XY, et al. Potassium channel subunit remodeling in rabbits exposed to long-term bradycardia or tachycardia: discrete arrhythmogenic consequences related to differential delayed-rectifier changes. Circulation 2006; 113 (3): 345-55

233. Li X, Huang CX, Jiang $\mathrm{H}$, et al. The beta-adrenergic blocker carvedilol restores L-type calcium current in a myocardial infarction model of rabbit. Chin Med J (Engl) 2005; 118 (5): 377-82

234. Varro A, Papp JG. Low penetrance, subclinical congenital LQTS: concealed LQTS or silent LQTS? Cardiovasc Res 2006; 70 (3): 404-6

235. Schlotthauer K, Bers DM. Sarcoplasmic reticulum $\mathrm{Ca}(2+)$ release causes myocyte depolarization: underlying mechanism and threshold for triggered action potentials. Circ Res 2000; 87 (9): 774-80

236. Volders PG, Sipido KR, Vos MA, et al. Cellular basis of biventricular hypertrophy and arrhythmogenesis in dogs with chronic complete atrioventricular block and acquired torsade de pointes. Circulation 1998; 98 (11): 1136-47

237. Volders PG, Sipido KR, Vos MA, et al. Downregulation of delayed rectifier $\mathrm{K}(+)$ currents in dogs with chronic complete atrioventricular block and acquired torsades de pointes. Circulation 1999; 100 (24): 2455-61
238. Tsuji Y, Opthof T, Yasui K, et al. Ionic mechanisms of acquired QT prolongation and torsades de pointes in rabbits with chronic complete atrioventricular block. Circulation 2002; 106 (15): 2012-8

239. Vos MA, de Groot SH, Verduyn SC, et al. Enhanced susceptibility for acquired torsade de pointes arrhythmias in the dog with chronic, complete AV block is related to cardiac hypertrophy and electrical remodeling. Circulation 1998; 98 (11): 1125-35

240. de Groot SH, Schoenmakers M, Molenschot MM, et al. Contractile adaptations preserving cardiac output predispose the hypertrophied canine heart to delayed afterdepolarization-dependent ventricular arrhythmias. Circulation 2000; 102 (17): 2145-51

241. Donker DW, Volders PG, Arts T, et al. End-diastolic myofiber stress and ejection strain increase with ventricular volume overload: serial in-vivo analyses in dogs with complete atrioventricular block. Basic Res Cardiol 2005; 100 (4): 372-82

242. Schoenmakers M, Ramakers C, van Opstal JM, et al. Asynchronous development of electrical remodeling and cardiac hypertrophy in the complete AV block dog. Cardiovasc Res 2003; 59 (2): 351-9

243. Sipido KR, Volders PG, de Groot SH, et al. Enhanced $\mathrm{Ca}(2+)$ release and $\mathrm{Na} / \mathrm{Ca}$ exchange activity in hypertrophied canine ventricular myocytes: potential link between contractile adaptation and arrhythmogenesis. Circulation 2000; 102 (17): 2137-44

244. Nattel S, Wang ZG, Matthews C. Direct electrophysiological actions of pentobarbital at concentrations achieved during general anesthesia. Am J Physiol 1990; 259 (6 Pt 2): H1743-51

245. Stadnicka A, Bosnjak ZJ, Kampine JP, et al. Modulation of cardiac inward rectifier $\mathrm{K}(+)$ current by halothane and isoflurane. Anesth Analg 2000; 90 (4): 824-33

246. Bachmann A, Mueller S, Kopp K, et al. Inhibition of cardiac potassium currents by pentobarbital. Naunyn Schmiedebergs Arch Pharmacol 2002; 365 (1): 29-37

247. Qi XY, Yeh YH, Chartier D, et al. The calcium/ calmodulin/kinase system and arrhythmogenic afterdepolarizations in bradycardia-related acquired long QT syndrome. Circulation Arrhythmia Electrophysiol 2009; 2(3): 295-304

248. Satoh Y, Sugiyama A, Takahara A, et al. A novel monkey proarrhythmia model that can predict the drug-induced torsades de pointes in clinical practice [abstract]. J Pharmacol Sci 2006; 100 Suppl. I: 223

249. Sugiyama A. Sensitive and reliable proarrhythmia in vivo animal models for predicting drug-induced torsades de pointes in patients with remodelled hearts. Br J Pharmacol 2008; 154 (7): 1528-37

250. Hashimoto K. Torsades de pointes liability inter-model comparisons: the experience of the QT PRODACT initiative. Pharmacol Ther 2008; 119 (2): 195-8

251. Kijtawornrat A, Nishijima Y, Roche BM, et al. Use of a failing rabbit heart as a model to predict torsadogenicity. Toxicol Sci 2006; 93 (1): 205-12

252. Schwartz PJ, Malliani A. Electrical alternation of the T-wave: clinical and experimental evidence of its relationship with the sympathetic nervous system and with the long Q-T syndrome. Am Heart J 1975; 89 (1): 45-50 
253. Surawicz B, Fisch C. Cardiac alternans: diverse mechanisms and clinical manifestations. J Am Coll Cardiol 1992; 20 (2): 483-99

254. Zareba W, Moss AJ, le Cessie S, et al. T wave alternans in idiopathic long QT syndrome. J Am Coll Cardiol 1994; 23 (7): 1541-6

255. Houltz B, Darpo B, Edvardsson N, et al. Electrocardiographic and clinical predictors of torsades de pointes induced by almokalant infusion in patients with chronic atrial fibrillation or flutter: a prospective study. Pacing Clin Electrophysiol 1998; 21 (5): 1044-57

256. Brockmeier K, Aslan I, Hilbel T, et al. T-wave alternans in LQTS: repolarization-rate dynamics from digital 12-lead Holter data. J Electrocardiol 2001; 34 Suppl.: 93-6

257. Shimizu W, Antzelevitch C. Cellular and ionic basis for T-wave alternans under long-QT conditions. Circulation 1999; 99 (11): 1499-507

258. Schmitt J, Baumann S, Klingenheben T, et al. Assessment of microvolt $\mathrm{T}$-wave alternans in high-risk patients with the congenital long-QT syndrome. Ann Noninvasive Electrocardiol 2009; 14 (4): 340-5

259. Berger RD. QT variability. J Electrocardiol 2003; 36 Suppl.: 83-7

260. Mine T, Shimizu H, Hiromoto K, et al. Beat-to-beat QT interval variability is primarily affected by the autonomic nervous system. Ann Noninvasive Electrocardiol 2008; 13 (3): $228-33$

261. Iwasa A, Hwa M, Hassankhani A, et al. Abnormal heart rate turbulence predicts the initiation of ventricular arrhythmias. Pacing Clin Electrophysiol 2005; 28 (11): 1189-97

262. Watanabe MA. Heart rate turbulence slope reduction in imminent ventricular tachyarrhythmia and its implications. J Cardiovasc Electrophysiol 2006; 17 (7): 735-40

263. Bass AS, Darpo B, Valentin JP, et al. Moving towards better predictors of drug-induced torsades de pointes. $\mathrm{Br} \mathrm{J}$ Pharmacol 2008; 154 (7): 1550-3

264. Bauman JL, Bauernfeind RA, Hoff JV, et al. Torsade de pointes due to quinidine: observations in 31 patients. Am Heart J 1984; 107 (3): 425-30

265. Chan AS, Isbister GK, Kirkpatrick CM, et al. Assessing risk of a prolonged QT interval: a survey of emergency physicians. Int J Emerg Med 2008; 1 (1): 35-41

266. Batchvarov VN, Ghuran A, Smetana P, et al. QT-RR relationship in healthy subjects exhibits substantial intersubject variability and high intrasubject stability. Am J Physiol Heart Circ Physiol 2002; 282 (6): H2356-63

267. Malik M, Camm AJ. Evaluation of drug-induced QT interval prolongation: implications for drug approval and labelling. Drug Saf 2001; 24 (5): 323-51

268. Hodges M. Rate correction of the QT interval. Card Electrophysiol Rev 1997; 1 (3): 360-3

269. Smetana P, Batchvarov V, Hnatkova K, et al. Circadian rhythm of the corrected QT interval: impact of different heart rate correction models. Pacing Clin Electrophysiol 2003 Jan; 26 (1 Pt 2): 383-6

270. Camm AJ. Clinical trial design to evaluate the effects of drugs on cardiac repolarization: current state of the art. Heart Rhythm 2005; 2 (2 Suppl.): S23-9

271. Letsas KP, Efremidis M, Kounas SP, et al. Clinical characteristics of patients with drug-induced QT interval prolongation and torsade de pointes: identification of risk factors. Clin Res Cardiol 2009; 98 (4): 208-12

272. Shah RR. If a drug deemed 'safe' in nonclinical tests subsequently prolongs QT in phase 1 studies, how can its sponsor convince regulators to allow development to proceed? Pharmacol Ther 2008; 119 (2): 215-21

273. Jonker DM, Kenna LA, Leishman D, et al. A pharmacokinetic-pharmacodynamic model for the quantitative prediction of dofetilide clinical QT prolongation from human ether-a-go-go-related gene current inhibition data. Clin Pharmacol Ther 2005; 77 (6): 572-82

274. Piccini JP, Whellan DJ, Berridge BR, et al. Current challenges in the evaluation of cardiac safety during drug development: translational medicine meets the Critical Path Initiative. Am Heart J 2009; 158 (3): 317-26

275. Heist EK, Ruskin JN. Drug-induced proarrhythmia and use of QTc-prolonging agents: clues for clinicians. Heart Rhythm 2005; 2 (2 Suppl.): S1-8

276. Makita N, Horie M, Nakamura T, et al. Drug-induced long-QT syndrome associated with a subclinical SCN5A mutation. Circulation 2002; 106 (10): 1269-74

277. Itoh H, Sakaguchi T, Ding WG, et al. Latent genetic backgrounds and molecular pathogenesis in drug-induced long-QT syndrome. Circ Arrhythm Electrophysiol 2009; 2 (5): $511-23$

278. Astrom-Lilja C, Odeberg JM, Ekman E, et al. Druginduced torsades de pointes: a review of the Swedish pharmacovigilance database. Pharmacoepidemiol Drug Saf 2008; 17 (6): 587-92

279. Peters RW, Gold MR. The influence of gender on arrhythmias. Cardiol Rev 2004; 12 (2): 97-105

280. Schrickel JW, Schwab JO, Yang A, et al. "Torsade de pointes" in patients with structural heart disease and atrial fibrillation treated with amiodarone, beta-blockers, and digitalis. Pacing Clin Electrophysiol 2006; 29 (4): 363-6

281. Di Cori A, Gemignani C, Bini R, et al. "Torsade de pointes" in a patient with variant angina. Ital Heart J 2004; 5 (7): 554-8

282. Kozhevnikov DO, Yamamoto K, Robotis D, et al. Electrophysiological mechanism of enhanced susceptibility of hypertrophied heart to acquired torsade de pointes arrhythmias: tridimensional mapping of activation and recovery patterns. Circulation 2002; 105 (9): 1128-34

283. Pedersen HS, Elming H, Seibaek M, et al. Risk factors and predictors of torsade de pointes ventricular tachycardia in patients with left ventricular systolic dysfunction receiving dofetilide. Am J Cardiol 2007; 100 (5): 876-80

284. Elming H, Brendorp B, Kober L, et al. QTc interval in the assessment of cardiac risk. Card Electrophysiol Rev 2002; 6 (3): 289-94

285. Samuelov-Kinori L, Kinori M, Kogan Y, et al. Takotsubo cardiomyopathy and QT interval prolongation: who are the patients at risk for torsades de pointes? J Electrocardiol 2009 Jul-Aug; 42 (4): 353-7

286. Choy AM, Darbar D, Dell'Orto S, et al. Exaggerated QT prolongation after cardioversion of atrial fibrillation. J Am Coll Cardiol 1999; 34 (2): 396-401

287. Koster RW, Wellens HJ. Quinidine-induced ventricular flutter and fibrillation without digitalis therapy. Am J Cardiol 1976; 38 (4): 519-23 
288. Badorff C, Zeiher AM, Hohnloser SH. Torsade de pointes tachycardia as a rare manifestation of acute enteroviral myocarditis. Heart 2001; 86 (5): 489-90

289. Sani IM, Solomon DS, Imhogene OA, et al. QT dispersion in adult hypertensives. J Natl Med Assoc 2006; 98 (4): 631-6

290. McLean A, Sceats G. Torsade de pointes associated with thyrotoxicosis. Intern Med J 2003; 33 (4): 207-8

291. Kearney P, Reardon M, O'Hare J. Primary hyperparathyroidism presenting as torsades de pointes. Br Heart J 1993; 70 (5): 473

292. Shimizu K, Miura Y, Meguro Y, et al. QT prolongation with torsade de pointes in pheochromocytoma. Am Heart J 1992; 124 (1): 235-9

293. Sade E, Oto A, Oner Z, et al. Adrenal adenoma presenting with torsade de pointes: a case report. Angiology 2002; 53 (4): 471-4

294. Danenberg HD, Hasin Y. Polymorphic ventricular tachycardia and repolarization abnormalities accompanying intracerebral hemorrhage. Circulation 2000; 101 (6): E81

295. Alehan D, Ceviz N, Celiker A. Torsade de pointes associated with encephalitis. Turk J Pediatr 1999; 41 (3): 395-8

296. Goldenberg I, Moss AJ. Long QT syndrome. J Am Coll Cardiol 2008; 51 (24): 2291-300

297. Trejbal K, Mitro P. ECG changes in alcoholic intoxication. Vnitr Lek 2008; 54 (4): 410-4

298. Anand S, Singh S, Nahar Saikia U, et al. Cardiac abnormalities in acute organophosphate poisoning. Clin Toxicol (Phila) 2009; 47 (3): 230-5

299. De Ponti F, Poluzzi E, Cavalli A, et al. Safety of nonantiarrhythmic drugs that prolong the QT interval or induce torsade de pointes: an overview. Drug Saf 2002; 25 (4): 263-86

300. Di Micoli A, Zambruni A, Bracci E, et al. "Torsade de pointes" during amiodarone infusion in a cirrhotic woman with a prolonged QT interval. Dig Liver Dis 2009; 41 (7): $535-8$

301. Schattner A, Gindin J, Geltner D. Fatal torsade de pointes following jaundice in a patient treated with disopyramide. Postgrad Med J 1989; 65 (763): 333-4

302. Reiffel JA, Appel G. Importance of QT interval determination and renal function assessment during antiarrhythmic drug therapy. J Cardiovasc Pharmacol Ther 2001; 6 (2): 111-9

303. Rottlaender D, Hoppe UC. Risks of non-prescription medication. Clobutinol cough syrup as a recent example. Dtsch Med Wochenschr 2008; 133 (4): 144-6

304. Piccirillo G, Magri D, Matera S, et al. Effects of pink grapefruit juice on QT variability in patients with dilated or hypertensive cardiomyopathy and in healthy subjects. Transl Res 2008; 151 (5): 267-72

305. Schrickel J, Bielik H, Yang A, et al. Amiodaroneassociated "torsade de pointes": relevance of concomitant cardiovascular medication in a patient with atrial fibrillation and structural heart disease. Z Kardiol 2003; 92 (10): 889-92

306. Singh BN, Gaarder TD, Kanegae T, et al. Liquid protein diets and torsade de pointes. JAMA 1978; 240 (2): 115-9

307. Chen IC, Chang KC, Hsieh YK, et al. Torsade de pointes due to consumption of Sauropus androgynus as a weightreducing vegetable. Am J Cardiol 1996; 78 (10): 1186-7
308. Marinucci P. Risk of torsades de pointes with non-cardiac drugs: grapefruit juice is source of potentially life threatening adverse drug reactions. BMJ 2001; 322 (7277): 47

309. Sagir A, Schmitt M, Dilger K, et al. Inhibition of cytochrome P450 3A: relevant drug interactions in gastroenterology. Digestion 2003; 68 (1): 41-8

310. Isner JM, Roberts WC, Heymsfield SB, et al. Anorexia nervosa and sudden death. Ann Intern Med 1985; 102 (1): 49-52

311. Suri R, Poist ES, Hager WD, et al. Unrecognized bulimia nervosa: a potential cause of perioperative cardiac dysrhythmias. Can J Anaesth 1999; 46 (11): 1048-52

312. Pringle TH, Scobie IN, Murray RG, et al. Prolongation of the QT interval during therapeutic starvation: a substrate for malignant arrhythmias. Int J Obes 1983; 7 (3): 253-61

313. Kocheril AG, Bokhari SA, Batsford WP, et al. Long QTc and torsades de pointes in human immunodeficiency virus disease. Pacing Clin Electrophysiol 1997; 20 (11): 2810-6

314. Paran Y, Mashav N, Henis O, et al. Drug-induced torsades de pointes in patients aged 80 years or more. Anadolu Kardiyol Derg 2008; 8 (4): 260-5

315. Hermans K, Stockman D, Van den Branden F. Grapefruit and tonic: a deadly combination in a patient with the long QT syndrome. Am J Med 2003; 114 (6): 511-2

316. Wilcock A, Beattie JM. Prolonged QT interval and methadone: implications for palliative care. Curr Opin Support Palliat Care 2009; 3 (4): 252-7

317. von Moltke LL, Greenblatt DJ, Duan SX, et al. In vitro prediction of the terfenadine-ketoconazole pharmacokinetic interaction. J Clin Pharmacol 1994; 34 (12): 1222-7

318. Honig PK, Wortham DC, Zamani K, et al. Terfenadineketoconazole interaction: pharmacokinetic and electrocardiographic consequences. JAMA 1993; 269 (12): 1513-8

319. Thanacoody RH, Daly AK, Reilly JG, et al. Factors affecting drug concentrations and QT interval during thioridazine therapy. Clin Pharmacol Ther 2007; 82 (5): 555-65

320. Priori SG, Schwartz PJ, Napolitano C, et al. Risk stratification in the long-QT syndrome. N Engl J Med 2003; 348 (19): 1866-74

321. Bednar MM, Harrigan EP, Ruskin JN. Torsades de pointes associated with nonantiarrhythmic drugs and observations on gender and QTc. Am J Cardiol 2002; 89 (11): 1316-9

322. Johnson JN, Ackerman MJ. QTc: how long is too long? Br J Sports Med 2009; 43 (9): 657-62

323. Viskin S. The QT interval: too long, too short or just right. Heart Rhythm 2009; 6 (5): 711-5

324. Shah RR. Cardiac repolarisation and drug regulation: assessing cardiac safety 10 years after the CPMP guidance. Drug Saf 2007; 30 (12): 1093-110

325. Fabritz L, Breithardt G, Kirchhof P. Preclinical testing of drug-induced proarrhythmia: value of transgenic models. Cardiovasc Hematol Agents Med Chem 2007; 5 (4): 289-94

Correspondence: Dr Stanley Nattel, Montreal Heart Institute Research Center, 5000 Bélanger Street E., Montreal, QC H1T 1C8, Canada.

E-mail: stanley.nattel@icm-mhi.org 